\title{
TRAF6 ubiquitinates TGF $\beta$ type I receptor to promote its cleavage and nuclear translocation in cancer
}

\author{
Yabing Mu1,2, Reshma Sundar 1,3, Noopur Thakur 1,2, Maria Ekman², Shyam Kumar Gudey ${ }^{1,2}$, Mariya Yakymovych², \\ Annika Hermansson', Helen Dimitriou ${ }^{1, \dagger}$, Maria Teresa Bengoechea-Alonso ${ }^{2, \uparrow}$, Johan Ericsson ${ }^{2, \uparrow}$, \\ Carl-Henrik Heldin² \& Marene Landström,2,3
}

Transforming growth factor $\beta$ (TGF $\beta$ ) is a pluripotent cytokine promoting epithelial cell plasticity during morphogenesis and tumour progression. TGF $\beta$ binding to type II and type I serine/threonine kinase receptors (T $\beta R I I$ and T $\beta R I$ ) causes activation of different intracellular signaling pathways. TRRI is associated with the ubiquitin ligase tumor necrosis factor receptor (TNFR)-associated factor 6 (TRAF6). Here we show that TGF $\beta$, via TRAF6, causes Lys63linked polyubiquitination of T $\beta R \mathrm{R}$, promoting cleavage of T $\beta R \mathrm{R}$ by TNF-alpha converting enzyme (TACE), in a PKC -dependent manner. The liberated intracellular domain (ICD) of $T \beta R I$ associates with the transcriptional regulator p300 to activate genes involved in tumour cell invasiveness, such as Snail and MMP2. Moreover, TGF $\beta$-induced invasion of cancer cells is TACE- and PKC $\zeta$ - dependent and the TRRI ICD is localized in the nuclei of different kinds of tumour cells in tissue sections. Thus, our data reveal a specific role for T $\beta R I$ in TGF $\beta$ mediated tumour invasion.

\footnotetext{
${ }^{1}$ Rudbeck Laboratory, Department of Immunology, Genetics and Pathology, SE-751 85 Uppsala, Sweden. ${ }^{2}$ Ludwig Institute for Cancer Research, Uppsala University, SE-751 24 Uppsala, Sweden. ${ }^{3}$ Medical Biosciences, Umeå University, SE-901 85 Umeå, Sweden. †Present addresses: Department of Pediatric Hemtology- Oncology, University of Crete, Medical School, Greece (H.D.); University College Dublin, School of Medicine and Medical Science, Conway Institute, Belfield, Dublin, Ireland (M.T.B.-A. and J.E.). Correspondence and requests for materials should be addressed to M.L. (email: Marene.Landstrom@licr.uu.se).
} 
T ransforming growth factor $\beta$ (TGF $\beta$ ) is a cytokine which plays an important role during normal embryogenesis due to its multifunctional effects on cellular responses such as proliferation, differentiation, apoptosis and migration. In recent years TGF $\beta$ has become recognized as a potent regulator of cellular plasticity which is a central event during embryogenesis and tumour progression. TGF $\beta$ signals through its binding to the type II and type I serine/threonine kinase receptors (T $\beta R I I$ and T $\beta R I$, respectively), to cause their hetero-oligomerization which subsequently activates different intracellular signaling pathways. TRRI phosphorylates the latent transcription factors Smad2 and Smad3 in early endosomes, to induce complex formation with Smad4 and nuclear translocation to regulate target genes ${ }^{1-4}$. T $\beta R I$ has been found to harbour a consensus binding site for the ubiquitin ligase tumor necrosis factor receptor (TNFR)-associated factor 6 (TRAF6); upon TGF $\beta$ binding TRAF6 activates the TGF $\beta$ activated kinase 1 (TAK1) - p38 mitogen activated protein (MAP) kinase pathway ${ }^{5,6}$. Interestingly, TNF-alpha converting enzyme (TACE) has recently been shown to cleave TRRI in its extracellular domain, which was demonstrated to cause a loss of TGF $\beta$-induced inhibition of proliferation of cells ${ }^{7}$.

Posttranslational modifications of proteins, such as monoubiquitination or Lys63-linked polyubiquitination, have emerged as an important mechanism to control the localization or function of the protein, whereas Lys48-linked polyubiquitination of proteins instead targets its substrate for proteasomal degradation ${ }^{8,9}$. TRAF6 is known to induce Lys63-linked polyubiquitination of its substrates, including TAK $1^{5}$.

The underlying molecular mechanisms for how TGF $\beta$ can both act as a tumour suppressor and a promoter remain to be fully understood. To further address how TGF $\beta$ promotes tumour progression, we have investigated the possibility that TRAF6 regulates the subcellular localization of TRRI by Lys63-dependent polyubiquitination and whether this is related to the capability of TGF $\beta$ to facilitate tumour invasion. We report here that TGF $\beta$ uses TRAF6, PKC $\zeta$ and TACE to promote the formation of an intracellular domain (ICD) of the TRRI that is translocated to the nucleus, where it promotes tumour invasion by induction of Snail and MMP2.

\section{Results}

Nuclear accumulation of the intracellular domain of T $\beta R I$. To investigate whether T $\beta R \mathrm{R}$ is proteolytically cleaved in human prostate cancer (PC-3U) cells, we ectopically expressed a C-terminally tagged constitutively active (ca) TRRI (HA-ALK5TD). Notably, in addition to the full length receptor, the HA antibody recognized a smaller fragment, corresponding to the estimated size of the intracellular part of T $\beta R I$ (Supplementary Fig. S1a). Using immunofluorescence and confocal microscopy, we next investigated the subcellular localization of endogenous T $\beta R I$ in PC-3U cells visualized by a antibodies raised against its intracellular, C-terminal part (V22) or its extracellular N-terminal part (H100; Fig. 1a). An enhanced nuclear accumulation of T $\beta R I$, or its C-terminal fragment, was noticed in TGF $\beta$-stimulated PC-3U cells, upon staining with the V22 antibody. In contrast, immunofluorescence staining revealed that the extracellular domain of the receptor, visualized by the H100antibody was mainly localized in the cell membrane in PC-3U cells stimulated with TGF $\beta$ for $6 \mathrm{~h}$ (Fig. 1a). To ensure the specificity of the V22 antibody in immunofluorescence and immunoblotting, siRNA was used to knock-down endogenous TRRI expression in PC-3U cells (Fig. 1a and Supplementary Fig. S1b); qRT-PCR was also used to demonstrate a substantial decrease of T $\beta R I$ mRNA expression (Supplementary Fig. S1b). The specificity of the V22 antibody used in our study was also verified by peptide blocking (Supplementary Fig. S1c).

To further validate the observation that T $\beta R I$, or its intracellular domain (ICD), is translocated to the nucleus in a TGF $\beta$-dependent manner, we performed a nuclear fractionation assay of cell lysates from TGF $\beta$-treated PC-3U cells. Immunoblotting of nuclear extracts by the V22 antibody revealed a T $\beta R I$ fragment of approximally $34 \mathrm{kDa}$, which was not recognized by the H100 antibody raised against the $\mathrm{N}$-terminal part of TRRI (Fig. 1b). In contrast, full-length T $\beta R I$ was observed in the cytoplasmic fraction, both by the V22 and $\mathrm{H} 100$ antibodies (Fig. 1b). While a pronounced increase of nuclear TRRI was detected by immunofluorescence only after TGF $\beta$ stimulation (Fig. 1a), nuclear T $\beta$ RI was detected by immunoblotting also in the absence of TGF $\beta$ stimulation (Fig. 1b). This discrepancy is probably due to the fact that sensitivity for detection of nuclear T $\beta R \mathrm{RI}$ is higher with the nuclear fractionation assay. To further investigate the TGF $\beta$-dependency of nuclear accumulation of TRRI, we expressed a fusion protein in which GFP was linked to the C-terminal part of T $\beta R I$ in PC-3U cells. The GFP-tagged T $\beta R I$ entered the nucleus of PC-3U cells after stimulation with TGF $\beta$ for $6 \mathrm{~h}$, while GFP expressed from a vector containing GFP alone did not (Fig. 1c). We also investigated the nuclear localization of ectopically expressed C-terminally HA-tagged ca T $\beta R I$ in PC-3U cells and observed a TGF $\beta$-induced accumulation of the HA-tagged ca TRRI-ICD (Supplementary Fig. S1d). This observation is consistent with the nuclear accumulation of endogenous TRRI-ICD as shown in Figure 1a,b. In further support of the notion that the N-terminal part of the T $\beta R I$ did not enter the nucleus, a HA-tagged TRRI with the tag localized $\mathrm{N}$-terminally between amino acid residues 27 and $28^{4}$, was found not to enter the nucleus in PC-3U cells with or without treatment with TGF $\beta$ (Supplementary Fig. S1e). Moreover, no TGF $\beta$-induced increase of the TRRI-ICD for N-terminal HAtagged TRRI was observed (Supplementary Fig. S1f). Together, these results suggest that the ICD of T $\beta R I$ enters into the nucleus in PC-3U cells in response to TGF $\beta$ stimulation.

Nuclear accumulation of TRRI is dependent on TRAF6. We have recently identified a consensus binding site for TRAF6 in T $\beta R^{5}{ }^{5}$. Ligand-induced oligomerization of the TGF $\beta$ receptor complex results in receptor kinase-independent activation of the enzymatic activity of TRAF6. This in turn causes Lys63-polyubiquitin-dependent activation of TGF $\beta$-activated kinase-1 (TAK1), causing activation of p38 MAPK in PC-3U cells. In contrast, activation of the canonical Smad pathway does not require TRAF6 ${ }^{5}$. To examine whether TRAF6 is important for the cleavage and nuclear accumulation of T $\beta R I$, we expressed C-terminally HA-tagged wild-type (wt) caT $\beta R I$ (HA-TßRI) or the HA-tagged caE161A (HA-E161A) receptor mutant which is unable to bind TRAF6, but still causes activation of the canonical Smad signalling pathway ${ }^{5}$. As shown in Figure 2a, stimulation of cells with TGF $\beta$ resulted in Lys63-linked polyubiquitination of wt T $\beta R I$, but not of the E161A mutant TRRI. Cleavage of the wt TRRI, as observed by immunoblotting of total cell lysate with HA antiserum was found to associate with its Lys63-linked polyubiquitination (Fig. 2a). Moreover, the E161A mutant TRRI failed to activate the p38 MAPK pathway while it was still able to activate Smad2, consistent with our previous report ${ }^{5}$ (Fig. 2a). In addition, knock-down of endogenous TRAF6 in PC-3U cells by siRNA, also resulted in loss of Lys63-linked polyubiquitination of T $\beta R I$, as well as loss of the formation of the TRRI ICD in response to stimulation with TGF 3 (Supplementary Fig. S2a,b). By using either Lys63 or Lys48 polyubiquitin-specific antibodies, we found that wt TRRI was Lys63-polyubiquitinated after $30 \mathrm{~min}$ of TGF $\beta$ stimulation, while no obvious sign of TGF $\beta$-induced Lys48-polyubiqutination of T $\beta R I$, was observed in this cell line during this time course (Fig. 2a and Supplementary Fig. S2a,c).

The pattern of polyubiquitination of TRRI was further examined using HA-tagged wt or mutant ubiquitin overexpressed in PC-3U cells. TGF $\beta$ stimulation induced polyubiquitination of T $\beta$ RI in PC$3 \mathrm{U}$ cells transiently transfected with a ubiquitin mutant in which all lysine residues where mutated except Lys63, while reduced ubiquitination was seen when a similar mutant retaining only Lys48 
a
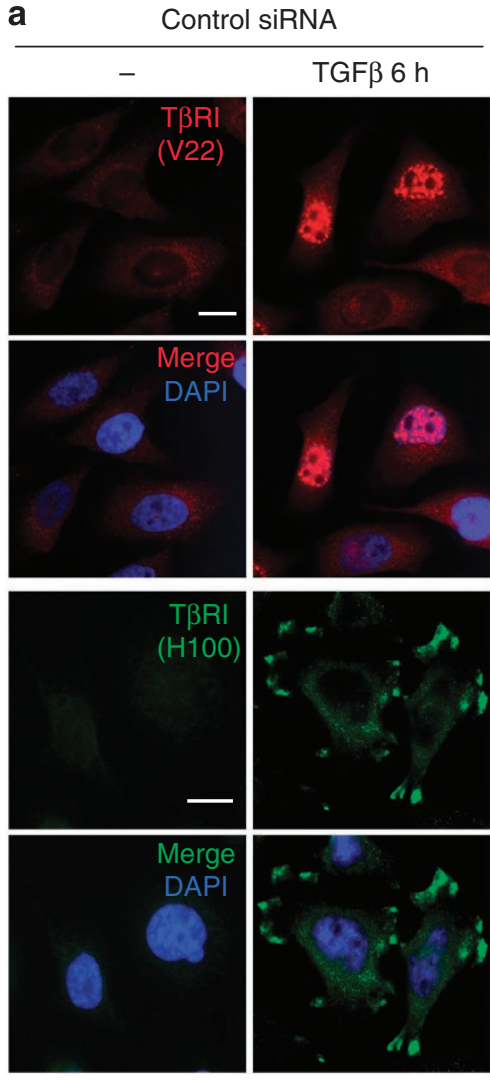

C
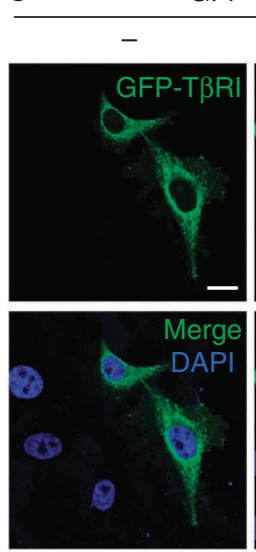

GFP-T $\beta R I$ TGF $\beta 6 \mathrm{~h}$
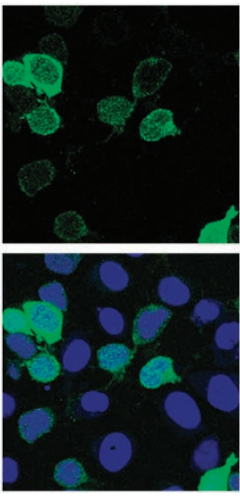

TGF $\beta 6 \mathrm{~h}$
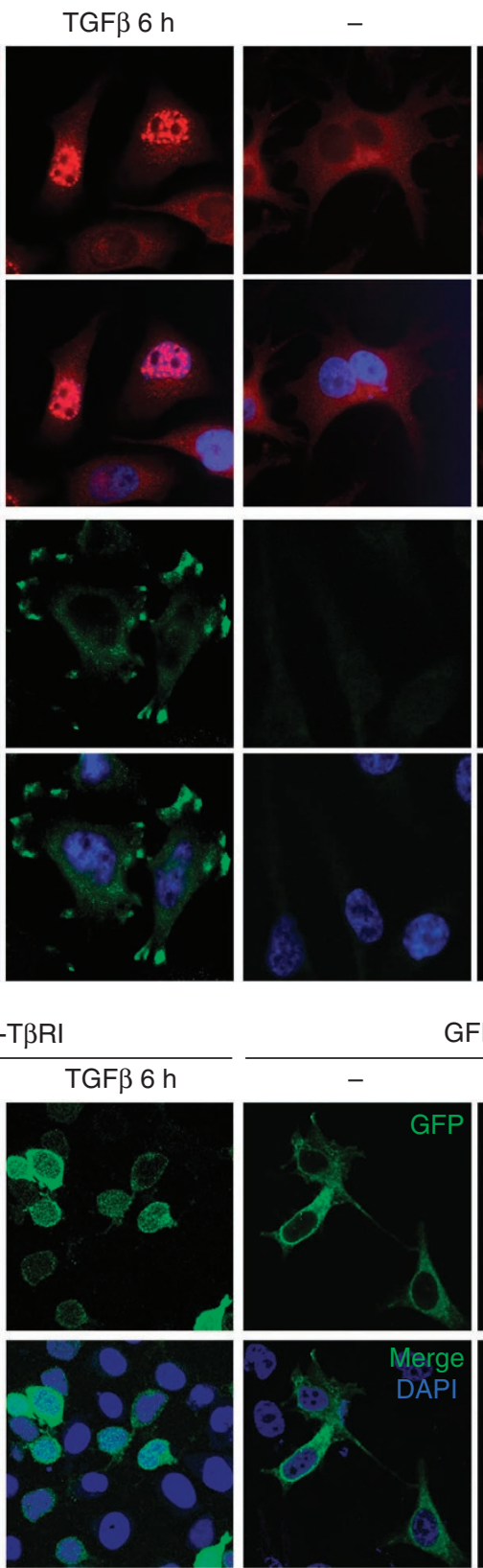

T $\beta R I$ SiRNA

TGF $\beta 6 \mathrm{~h}$
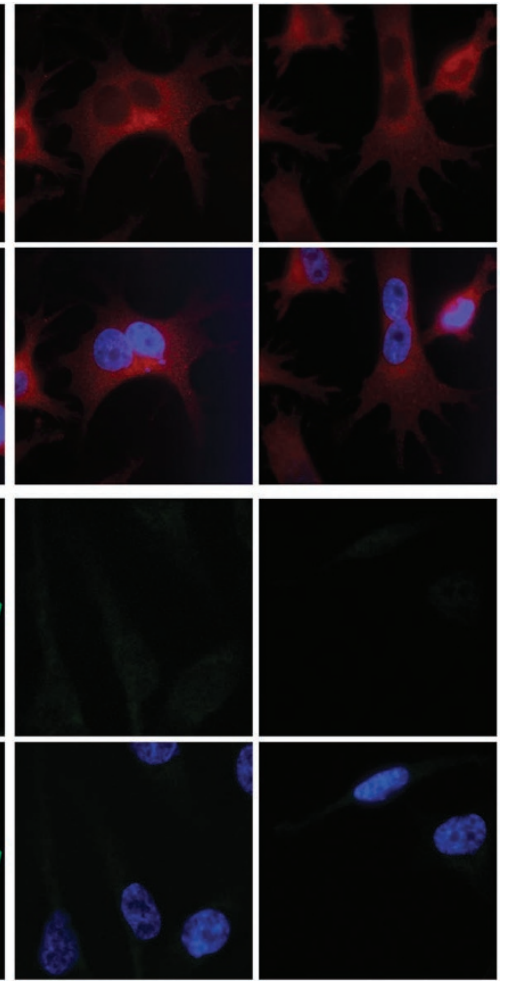

GFP
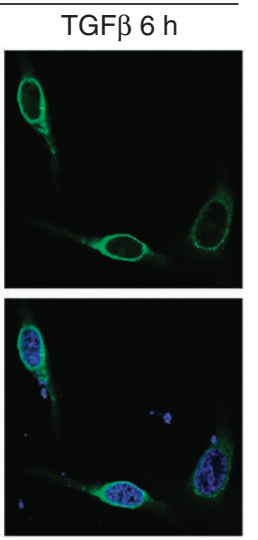

b

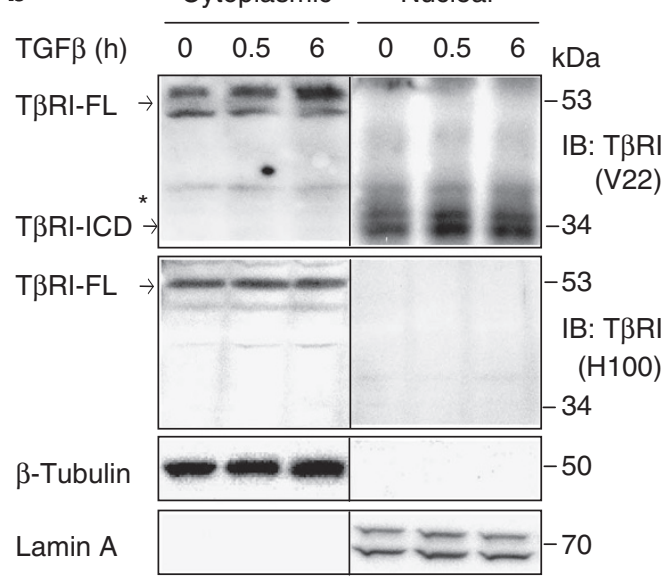

Figure 1 | TGF $\boldsymbol{\beta}$ induces nuclear accumulation of T $\beta \mathbf{R I}$ intracellular domain (T $\boldsymbol{\beta} \mathbf{R I}-\mathbf{I C D})$. ( $\mathbf{a}, \mathbf{b})$ Knockdown of T $\beta R I$ by siRNA was performed to demonstrate the specificity of the $\mathrm{V} 22$ and $\mathrm{H} 100$ antibodies, which recognize the intracellular and extracellular domain of T $\beta R \mathrm{R}$, respectively, in immunofluorescence (a; DAPI was used to visualize cell nuclei, scale bar $20 \mu \mathrm{m}$ ). (b) Cell lysates of PC-3U cells treated or not with TGF $\beta$, were fractionated into cytoplasmic and nuclear proteins and subjected to SDS-gel electrophoresis, followed by immunoblotting using V22 and H100 antibodies. $\beta$-tubulin and lamin A served as controls for the cytoplasmic and nuclear fractions, respectively. Molecular weight markers are indicated. (c) Representative confocal microscopy pictures of C-terminally pEGFP-N3-tagged wt TRRI (GFP-T $\beta R I$ ) and pEGFP-N3-vector (GFP) expressed in PC$3 \mathrm{U}$ cells treated with TGF $\beta$ for $6 \mathrm{~h}$ are shown (left panel) and quantified in right panel (mean \pm s.d., $n=3-5$ independent experiments where $N=350$ cells where counted in each group, ${ }^{\star} P<0.0002$, ANOVA). Cell nuclei were stained with DAPI. Scale bar $20 \mu \mathrm{m}$.

was expressed (Fig. 2b). In addition, TRAF6 was shown to induce the polyubiquitination of T $\beta \mathrm{RI}$ in an in vitro ubiquitination assay, providing firm evidence that T $\beta R I$ is a substrate for TRAF6 (Supplementary Fig. S3).

TGF $\beta$-induced nuclear accumulation of ectopically expressed C-terminal HA-tagged caT $\beta R I$ in PC-3U cells occurred more efficiently for the wt T $\beta$ RI than for the E161A mutant HA-T $\beta R I$, as analyzed by immunofluorescence (Fig. 2c). On the basis of these data, we conclude that TRAF6 causes Lys63-dependent polyubiquitination of T $\beta R I$ in a TGF $\beta$-dependent manner which correlates with generation of an intracellular fragment of T $\beta R I$ and its nuclear accumulation.

T $\beta$ RI is cleaved by TACE. The metalloproteases TNF-alpha converting enzyme (TACE)/ADAM17 and ADAM10, when activated, cleave certain receptors and adhesion proteins, just outside the cell membrane. TACE has recently been shown to cleave T $\beta R I$ in an ERK MAP-kinase dependent manner, leading to desensitiza- 
a

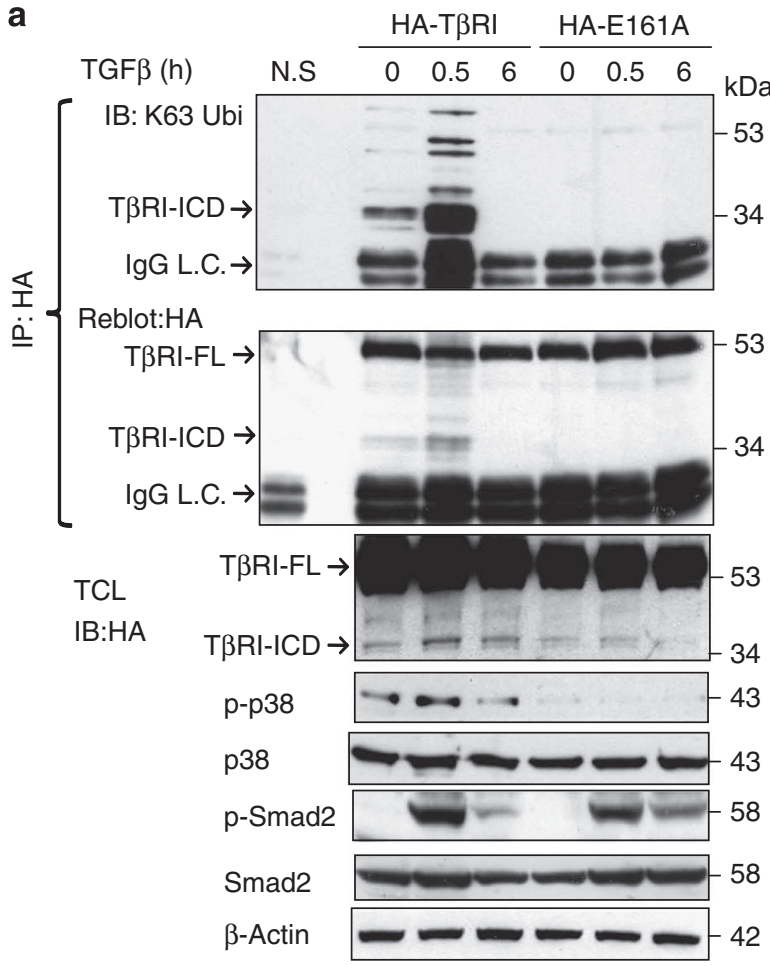

b
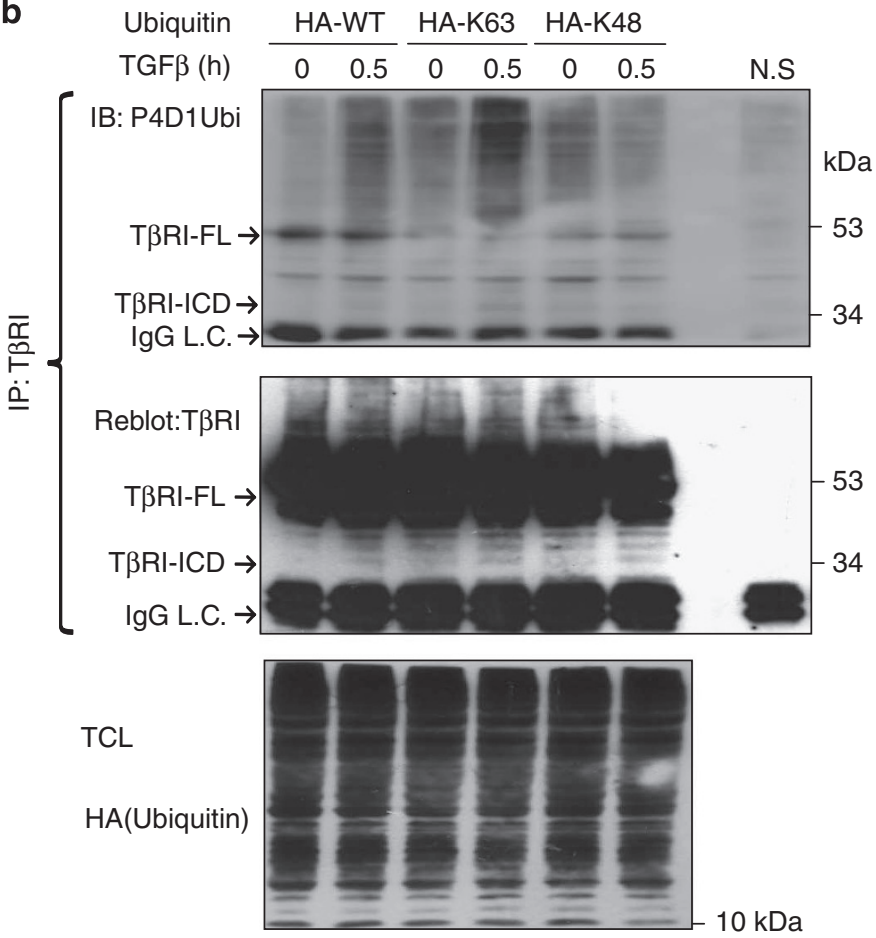

Ubiquitin TGF $\beta$ (h)

IB: P4D1Ubi

T $\beta$ RI-FL

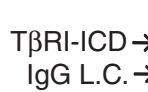

Reblot:T $\beta$ R

TCL

HA(Ubiquitin)

$10 \mathrm{kDa}$
C
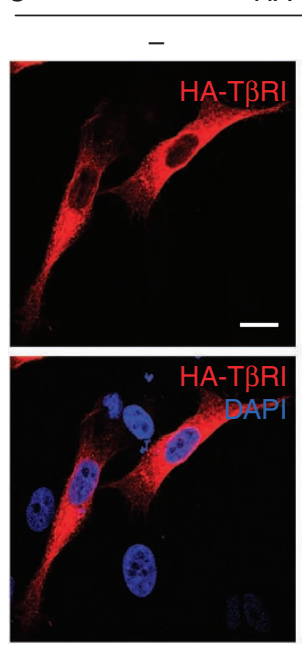

HA-T $\beta$ RI

TGF $\beta 0.5 \mathrm{~h}$
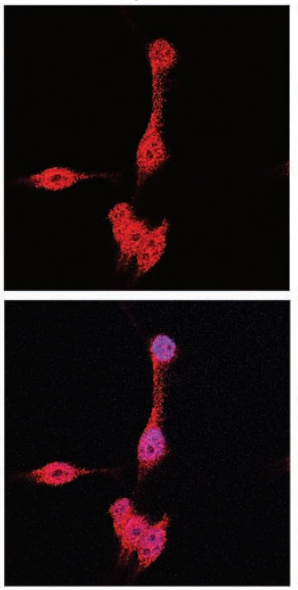

$\mathrm{kDa}$

53

34

(1)

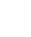

$\frac{\mathrm{HA}-\mathrm{E} 161 \mathrm{~A}}{-\quad \mathrm{TGF} \beta 0.5 \mathrm{~h}}$
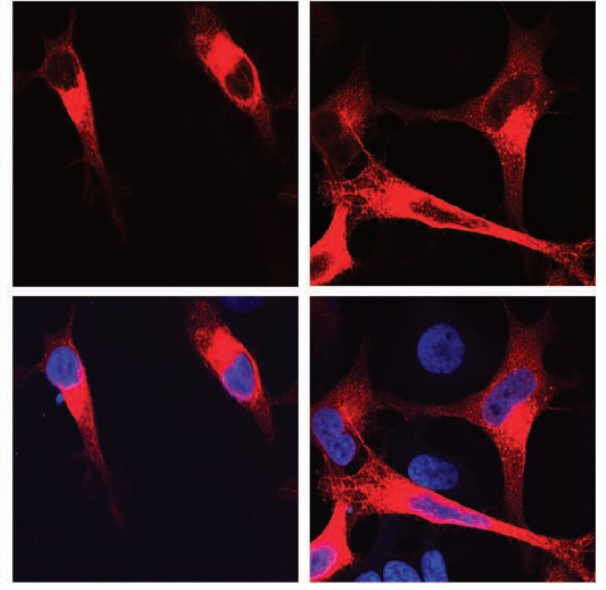

Figure 2 | TRAF6 promotes Lys63-dependent polyubiquitination of wt T $\beta$ RI but not of the E161A mutant T $\beta R I$. (a) PC-3U cells transiently transfected with C-terminally HA-tagged wt T $\beta R$ I, or E161A mutant T $\beta R$ I deficient in association with TRAF6, were treated or not with TGF $\beta$, whereafter ubiquitination of T $\beta R I$ was examined by an in vivo ubiquitination assay. Complexes immunoprecipitated (IP) with anti-HA antibodies were immunoblotted (IB) with Lys63 (K63)-linked polyubiquitin-specific antibody. A light-chain specific secondary antiserum was used to avoid cross-reaction with IgG heavy chain. Molecular weight markers are indicated. Another part of the corresponding total cell lysates (TCL) was subjected to immunoblotting for HA to detect the T $\beta R I-I C D$ fragment, and activation of $\mathrm{p} 38$ and Smad2, by phospho-specific antisera. The filters were then reprobed with total p38 or Smad2, to verify specificity of phospho-specific antisera and actin served as internal control for equal loading of proteins. (b) In vivo ubiquitination assays performed in PC$3 \mathrm{U}$ cells transiently transfected with HA-tagged wt, K63- and K48-only ubiquitin. Cell lysates were immunoprecipitated with V22 antibody against T $\beta R I$, and K63-dependent polyubiquitination was visualized by immunoblotting with P4D1-antiserum. A light-chain specific secondary antiserum was used to avoid cross-reaction with lgG heavy chain. The TCL-filter was subjected to immunoblotting with an HA-antibody to verify equal expression levels of ubiquitin. (c) PC-3U cells ectopically expressing C-terminally HA-tagged wt T $\beta R$ I or the corresponding E161A mutant were stimulated with TGF $\beta$ for $0.5 \mathrm{~h}$ and thereafter stained with an HA antibody. Staining with DAPI was used to visualize cell nuclei. Scale bar $20 \mu \mathrm{m}$.

tion of TGF $\beta$ signaling ${ }^{7}$. TACE is often overexpressed in tumours and is activated by $\mathrm{PKC}^{10}$. To further characterize the molecular mechanisms behind the cleavage and nuclear translocation of T $\beta R I$, we examined the possible involvement of the metalloproteinase TACE/ADAM17. Treatment of human PC-3U cells with
TPA to activate $\mathrm{PKC}^{10}$ led to nuclear accumulation of endogenous TßRI or its ICD, as shown by immunofluorescence (Fig. 3a). Moreover, when PC-3U cells expressing the C-terminally tagged HA-caT $\beta R I$ were treated with TGF $\beta$ or TPA, the ICD accumulated in the nuclear fraction (Fig. 3b). Pretreatment of cells with 
a

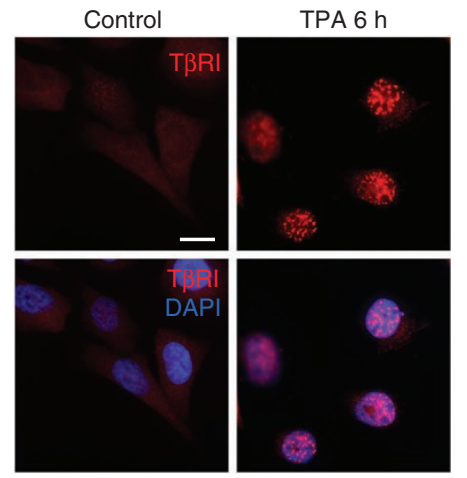

b

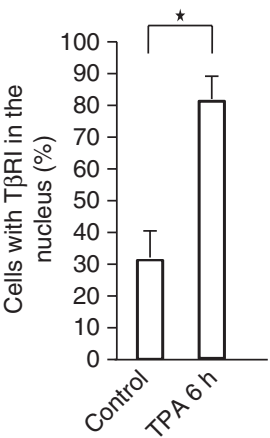

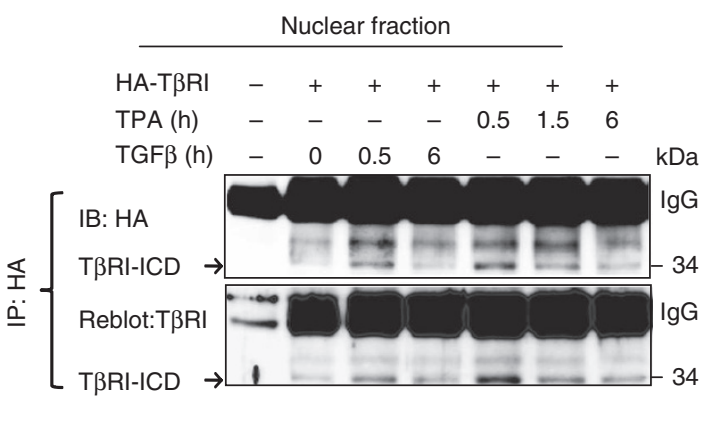
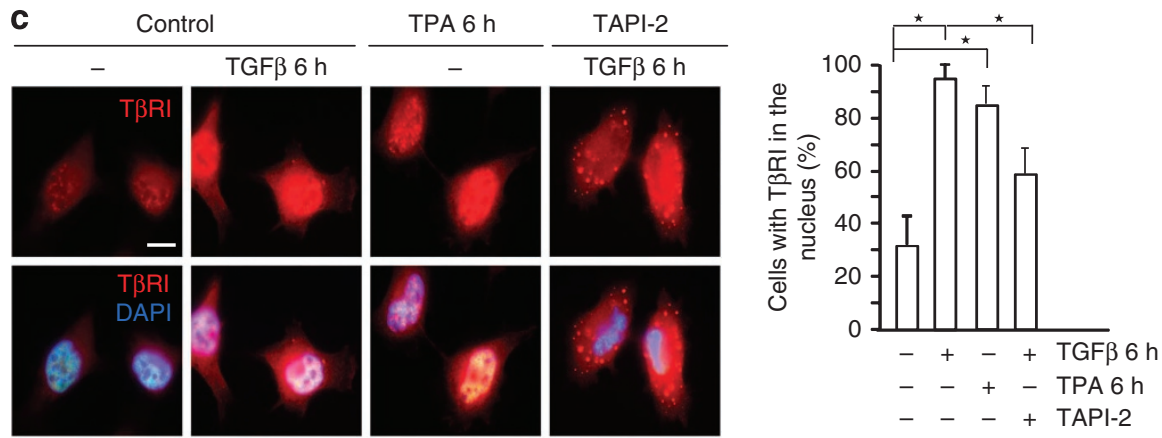

d

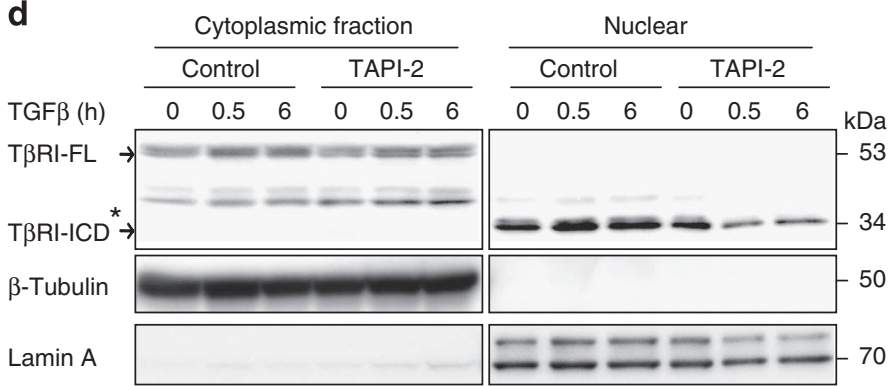

e
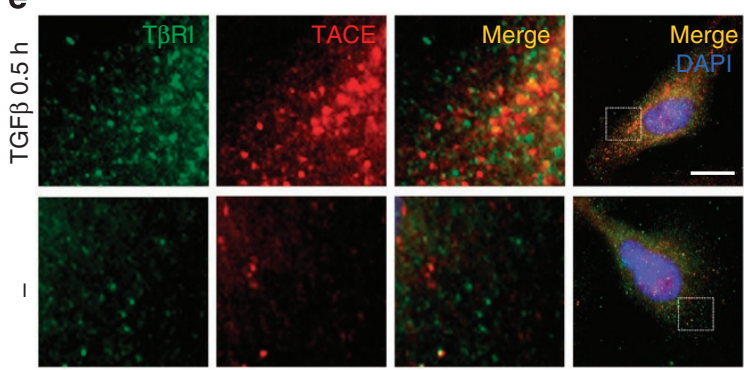

Figure 3 | TACE regulates nuclear accumulation of T $\beta$ RI ICD. (a) PC-3U cells were treated with TPA for 6 h. Endogenous T $\beta R$ I is shown by immunofluorescence using the V22 antibody. Quantification of the number of cells showing endogenous T $\beta R I$ in the nucleus is shown on the right side of the panel (mean \pm s.d., $n=3$ independent experiment, where $N=200-300$ cells where counted in each group, ${ }^{*} P<0.0001, A N O V A$ ). Scale bar $20 \mu m$. (b) Nuclear proteins from PC-3U cells transiently transfected with C-terminally HA-tagged T $\beta R$ I were treated as indicated, then samples were subjected to immunoprecipitation with an HA antibody. The T $\beta R I-I C D$ was visualized by immunoblotting with an $\mathrm{HA}$ antibody and the membrane was thereafter stripped and reblotted with VPN antiserum against the intracellular part of the receptor. (c) PC-3U cells were treated with either TGF $\beta$ or TPA alone for $6 \mathrm{~h}$ or with both TGF $\beta$ and TAPI-2 for $6 \mathrm{~h}$. Endogenous T $\beta \mathrm{RI}$ is shown by immunofluorescence using the $\mathrm{V} 22$ antibody. Quantification of the number of cells showing endogenous T $\beta R I$ in the nucleus is shown on the right side of the panel (mean \pm s.d, $n=3$ independent experiments, where $N=200-300$ cells where counted from each group, ${ }^{\star} P<0.0001$, ANOVA). Scale bar $20 \mu \mathrm{m}$. (d) Cell lysates of PC-3U cells treated with TGF $\beta$ in the presence or absence of TAPI-2 as indicated, were fractionated into cytoplasmic and nuclear proteins and subjected to SDS-gel electrophoresis, followed by immunoblotting using V22 antibody, which recognizes both the T $\beta R I$ full length (T $\beta R I-F L)$ and intracellular domain of T $\beta R I$ (T $\beta R I-I C D)$. $\beta$-tubulin and lamin A served as controls for the cytoplasmic and nuclear fractions, respectively. Molecular weight markers are indicated. *indicates a background band. (e) PC-3U cells were with treated or not with TGF $\beta$ for $0.5 \mathrm{~h}$. Endogenous TACE and T $\beta$ RI are shown by co-immunofluorescence using TACE (TRITC) and V22 (FITC) antisera. Their colocalization is demonstrated by the yellow colour as shown in merge. The pictures are enlargements of the picture to the right (white box). Scale bar $20 \mu \mathrm{m}$. Stainings with DAPI was used to visualize cell nuclei in (a, $\mathbf{c}$ and $\mathbf{e})$.

TAPI-2, an inhibitor of TACE, led to a decreased nuclear entrance of the ICD of endogenous T $\beta$ RI in response to TGF $\beta$ stimulation (Fig. 3c,d). As TACE was shown recently to associate with the ectopically expressed T $\beta$ RI in cells expressing HER2 ${ }^{11}$, we investigated by co-immunofluorescence if endogenous T $\beta R I$ associated with TACE in PC-3U cells. A TGF $\beta$-induced colocalization of T $\beta$ RI and TACE was observed (Fig. 3e). From these data, we conclude that activation of TACE, either by TPA-treatment of cells or stimulation with TGF $\beta$, leads to accumulation of the $\mathrm{T} \beta \mathrm{RI}$ ICD in the nucleus.
Determination of the TACE cleavage site in T $\beta$ RI. Previous studies have shown that TACE has a strong preference for cleavage at Ala-Val sequences ${ }^{12}$ or Gly-Leu sequences ${ }^{13}$. T $\beta R I$ contains two Gly-Leu sequences, located at position Gly52 and Gly120. To investigate the possibility that TACE cleaves T $\beta R I$ at Gly120, which is located close to the transmembrane domain, we mutated Gly 120 to Ile (G120I) in T $\beta$ RI. The G120I mutant T $\beta$ RI did not undergo cleavage in response to TGF $\beta$ stimulation (Fig. 4a), suggesting that TACE cleaves T $\beta R I$ at the Gly-Leu bond at position 120-121. The kinase activity of the G120I mutant was intact as judged by its 
a

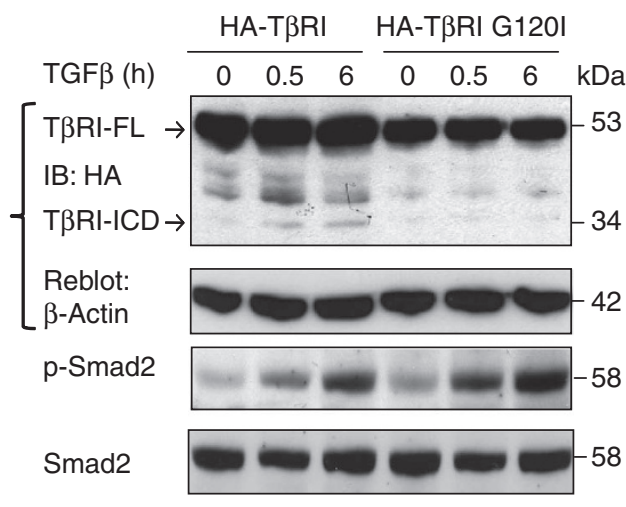

b

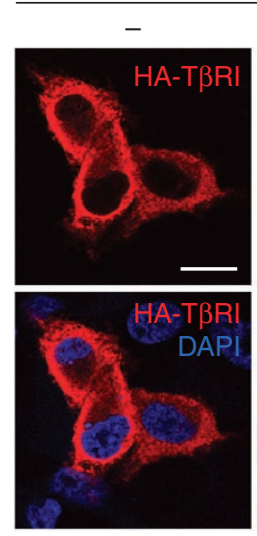

HA-T $\beta$ RI

TGF $\beta 0.5 \mathrm{~h}$
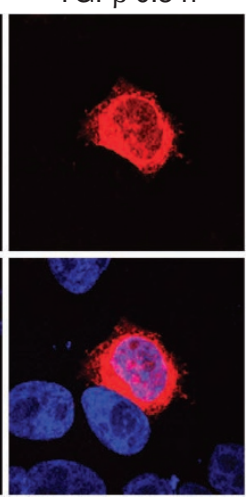

HA-TßRI G120I

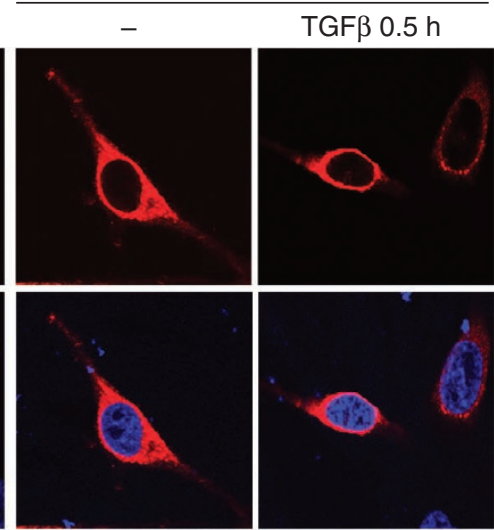

Figure 4 | Identification of the TGF $\beta$-induced cleavage site for TACE in the extracellular domain of T $\beta R I$. (a) Total cell lysates derived from PC-3U cells transiently transfected with C-terminally HA-tagged wt T $\beta R$ I or the corresponding G12OI mutant were stimulated with TGF $\beta$ as indicated, was subjected to immunoblotting for HA to detect the T $\beta$ RI-ICD fragment. The filter was reprobed with $\beta$-actin antibodies to show equal loading of proteins in all lanes, and activation of Smad2, by a phospho-specific antiserum ( $p$-Smad2). The $p$-Smad2 filter was reblotted with total Smad2. (b) Representative confocal microscopy pictures of PC-3U cells ectopically expressing C-terminally HA-tagged wt T $\beta R I$ or the corresponding G120I mutant were stimulated with TGF $\beta$ for $0.5 \mathrm{~h}$ and thereafter stained with HA antibody. Staining with DAPI was used to visualize cell nuclei. Scale bar $20 \mu \mathrm{m}$.

ability to phosphorylate Smad2, when compared with wt T $\beta$ RI. Moreover, the G120I mutant T $\beta$ RI did not accumulate in the nucleus in response to TGF $\beta$ stimulation (Fig. $4 \mathrm{~b}$ ).

PKC $\zeta$ is needed for TACE-induced cleavage of T $\beta$ RI. We next investigated whether PKC $\zeta$, which is the only member in the PKCfamily known to form a multiprotein-complex with TRAF6 ${ }^{14}$, is involved in cleavage of T $\beta R I$ and nuclear translocation of the ICD. Inhibition of $\mathrm{PKC} \zeta$, by $\mathrm{PKC} \zeta$ pseudosubstrate, completely prevented nuclear accumulation of the TRRI ICD in a dose-dependent manner (Fig. 5a and Supplementary Fig. S4a). It is well accepted that the classical members of the PKC family are activated by TPA, while atypic $\mathrm{PKC}$ isoforms like $\mathrm{PKC} \zeta$ are thought not to be activated by $\mathrm{TPA}^{15,16}$. However, we found that $\mathrm{PKC} \zeta$ is activated as a result of stimulation of cells by TGF $\beta$, as well as by TPA (Fig. 5b). TGF $\beta$ stimulation did not lead to activation of PKC $\zeta$ in $\mathrm{TRAF}^{-1-} \mathrm{MEFs}$ (Fig. 5c), supporting the notion that TRAF6 is important for TGF $\beta$ induced activation of $\mathrm{PKC} \zeta$. Using a nuclear fractionation assay, we noticed a significant loss of TGF $\beta$-induced nuclear accumulation of T $\beta$ RI ICD after siRNA-mediated silencing of PKC $\zeta$ (Fig. $5 \mathrm{~d}$ ). In addition, ectopic expression of wt $\mathrm{PKC} \zeta$ promoted expression and cleavage of caT $\beta$ RI or kinase dead (KD) T $\beta R I$ mutant (Fig. 5e). Treatment of PC-3U cells with the PKC $\zeta$ inhibitor decreased the formation of the ICD of C-terminally HA-tagged ca T $\beta$ RI in TGF $\beta$ treated cells as well as in a dose-dependent manner (Supplementary Fig. S4b,c), while treatment with the T $\beta$ RI kinase inhibitor SB505124 had no major effect (Fig. 5f).

Using immunofluorescence stainings, we observed TGF $\beta$ induced co-localization of endogenous T $\beta R I$ and TACE. Adding the PKC $\zeta$ pseudosubstrate to cells prevented the co-localization (Fig. 5g), suggesting that PKCל activity is needed for a proper localization of T $\beta$ RI to a subcellular compartment where it can be cleaved by TACE. In conclusion, TGF $\beta$ causes activation of $\mathrm{PKC} \zeta$ in a TRAF6-dependent manner, which is important for the proteolytic cleavage of the T $\beta$ RI by TACE, leading to nuclear accumulation of T $\beta R I$ ICD.

T $\beta$ RI ICD regulates transcription. The observation that the ICD of T $\beta R I$ enters the nucleus in TGF $\beta$-treated PC-3U cells, suggests that it might participitate in gene regulation. To search for a link between the nuclear T $\beta$ RI ICD and gene transcription, we investi- gated if T $\beta$ RI ICD associates with the well-known transcriptional regulator $\mathrm{p} 300$. TGF $\beta$ treatment of PC-3U cells led to a co-localization of T $\beta R I$ and p300 in nuclear specles (Fig. 6a), which we identified by co-immunofluorescence as promyelocytic leukemia protein (PML) nuclear bodies ${ }^{17}$ (Fig. 6b). Treatment of cells with the PKC $\zeta$ pseudosubstrate prevented the co-localization of T $\beta R I$ with PML nuclear bodies (Fig. 6b). By co-immunoprecipitation experiments, the acetyltransferase p300 was found to associate with TRRI ICD in vivo (Fig. 6c,d) and we used an acetyl-lysine antibody to verify that T $\beta$ RI ICD is acetylated (Fig. 6e). In contrast, in cells expressing the E161A mutant T $\beta$ RI, less ICD was associated with endogenous p300 and less acetylated ICD was detected (Fig. 6d,e). We observed that the level of p300 was lower in cells transfected with the E161A mutant T $\beta R I$ unable to bind TRAF6, compared to wt T $\beta R I$ (Fig. 6d). Using qRT-PCR, a TGF $\beta$-induced increase of p300 mRNA expression was observed in cells transiently transfected with wt T $\beta R I$, but not in cells transfected with E161A mutant T $\beta$ RI (Fig. 6f). This suggests that TGF $\beta$ induces p300 in a TRAF6-dependent manner.

Next, we used qRT-PCR to analyze the effect of T $\beta$ RI ICD on known TGF $\beta$ target genes. Snail and MMP2 mRNA expressions were induced by wt T $\beta$ RI but much less by the E161A mutant T $\beta R I$, whereas PAI1 and Smad7 were induced by both wt and E161A mutant T $\beta R I$ (Fig. 6g). A chromatin immunoprecipitation (ChIP) assay revealed binding of T $\beta$ RI or T $\beta R I$ ICD to the endogenous Snail promoter in a TGF $\beta$-dependent manner in PC-3U cells (Fig. 6h). Since expression of Snail and MMP2 genes is linked to tumour invasiveness ${ }^{18}$, we examined PC-3U cells expressing wt or E161A mutant T $\beta R I$ using an invasion assay. Interestingly, we observed that TGF $\beta$-induced invasion occurred in PC-3U cells only when wt T $\beta$ RI was expressed, whereas epidermal growth factor (EGF) stimulated invasion both in cells expressing wt or mutant T $\beta R I$ (Fig. 6i, right panel shows optical density (OD) mean values of stained invasive tumour cells). Similar results were observed when the experiment was repeated using the human prostate cancer cell line LNCaP; TGF $\beta$ treatment of LNCaP cells expressing wt T $\beta$ RI, but not the E161A mutant T $\beta$ RI, promoted their invasion (Supplementary Fig. S5a,b). Thus, our data propose that the T $\beta$ RI ICD associates with p300 in nuclear PML bodies in a PKC $\zeta$-dependent manner, and is acetylated by p300. Moreover, Snail and MMP2 are induced by T $\beta$ RI ICD, correlating with an increased invasiveness of cells. 
a

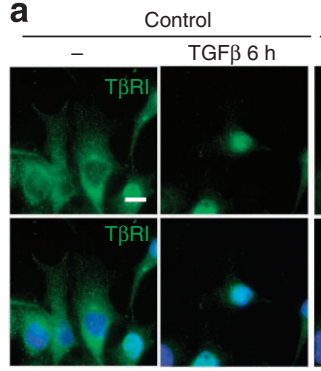

b

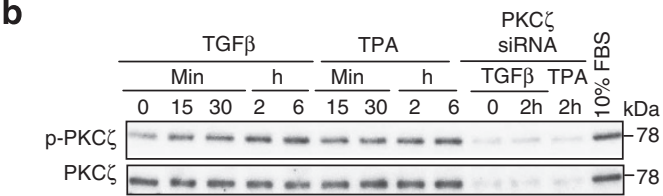

e

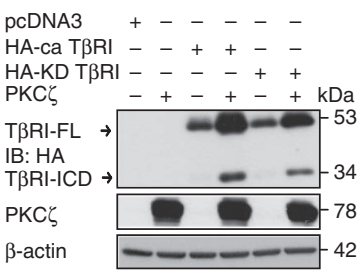

PKC $\zeta$ pseudosubstrate

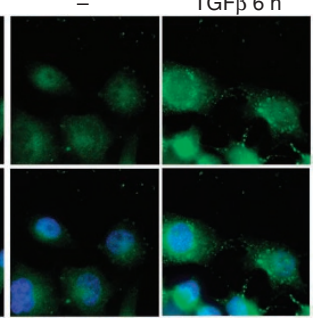

C

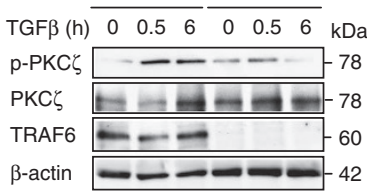

d

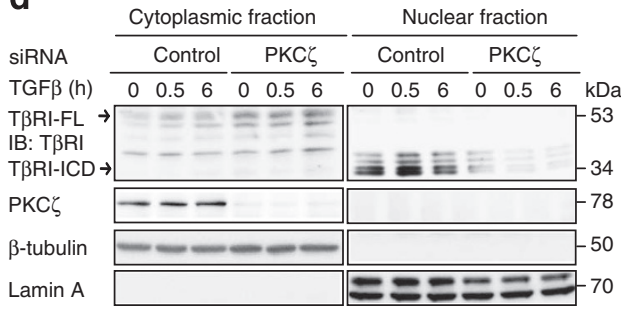

g

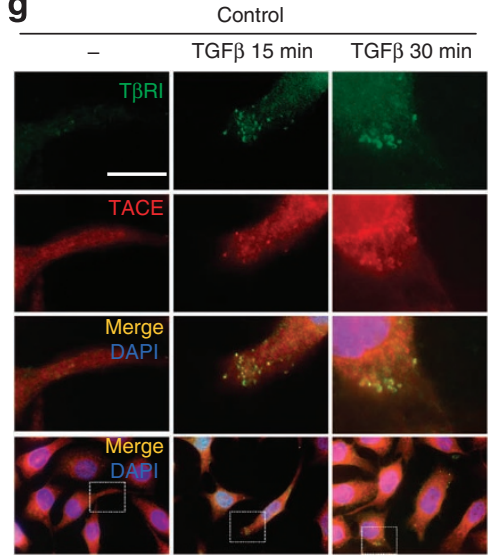

PKC $\zeta$ pseudosubstrate

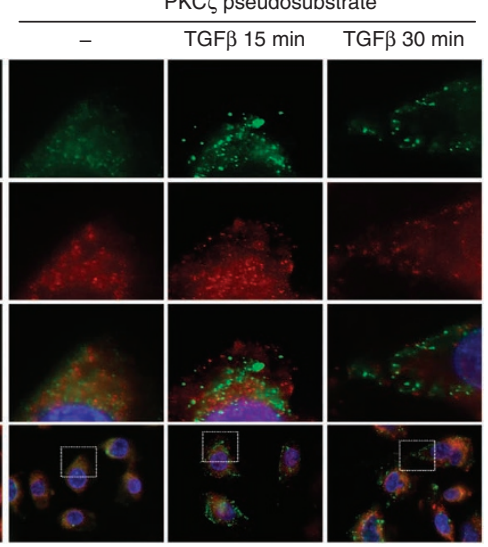

Figure $\mathbf{5}$ | PKC $\zeta$ promotes nuclear accumulation of T $\boldsymbol{\beta R R I . ~ ( a ) ~ I m m u n o f l u o r e s c e n c e ~ o f ~ e n d o g e n o u s ~ T ~} \beta R$ I visualized with the V22 antibody in PC-3U cells treated with TGF $\beta$ with or without PKC $\zeta$ pseudosubstrate to inhibit PKC $\zeta$. Scale bar $20 \mu \mathrm{m}$. (b) Cell lysates from PC-3U cells treated with TGF $\beta$ or TPA were subjected to immunoblotting with PPKC $\zeta$ antibody. Total cell lysates from cells transiently transfected with PKC $\zeta$ siRNA served as negative control and cells treated with $10 \%$ FBS as positive control. The filter was reprobed with PKC $\zeta$ antiserum to show equal loading of proteins in all lanes. (c) Cell lysates from wt and TRAF6 ${ }^{-1-}$ MEFs was subjected to immunoblotting for $\mathrm{p}-\mathrm{PKC} \zeta, / \mathrm{PKC} \zeta$, TRAF6 and $\beta$-actin antibodies to show activation of PKC $\zeta_{\text {, }}$ knock down of TRAF6, and equal loading of proteins in all lanes, respectively. (d) PC-3U cells, in which endogenous PKC $\zeta$ was silenced by its siRNA or not, and then treated with TGF $\beta$, were subjected to cell fractionation followed by SDS-gel electrophoresis and immunoblotting to investigate the subcellular localization of endogenous T $\beta R I$. Lamin A and $\beta$-tubulin served as controls for the nuclear and cytoplasmic fractions, respectively.

(e) Cell lysates from PC-3U cells transiently transfected and treated as indicated, in the presence or absence of wt PKC $\zeta$, subjected to immunoblotting to visualize T $\beta R$ I-FL and T $\beta R I-I C D$. Immunoblotting of cell lysates for PKC $\zeta$ and $\beta$-actin served as controls for the experiment. (f) Cell lysates from PC-3U cells transiently transfected with C-terminally HA-tagged wt TRRI and wt PKC $\zeta$, and treated with TGF $\beta$ in the presence and absence of T $\beta R I$ inhibitor (SB505124), subjected to immunoblotting for HA to visualize T $\beta R I-F L$ and T $\beta R I-I C D$. Immunoblotting of cell lysates for PKC $\zeta$, $p$-Smad2 and $\beta$-actin served as controls for the experiment. (g) PC-3U cells were treated with TGF $\beta$, with or without the PKC $\zeta$ pseudosubstrate. Endogenous TACE and T $\beta R I$ were visualized by immunofluorescence using TACE (TRITC) and V22 (FITC) antisera. Their colocalization is demonstrated by the yellow colour as shown in merge. Scale bar $20 \mu \mathrm{m}$. Stainings with DAPI was used to visualize cell nuclei in $\mathbf{a}, \mathbf{g}$.

Nuclear TßRI ICD is observed in malignant prostate cells. We observed that the nuclear entrance of T $\beta R I$ was associated with invasiveness of prostate cancer cells; therefore, we used immunofluorescence and confocal microscopy to investigate the subcellular localization of endogenous T $\beta R I$, in primary human prostate epithelial cells (PrEC) cells and PC-3U cells, visualized by the V22 antibody raised against its C-terminal part (Fig. 6j,k). Intriguingly, accumulation of T $\beta$ RI or its ICD in the nucleus took place in malignant PC-3U cells, but not in normal PrEC cells, where T $\beta$ RI was retained in cell-cell contacts, also after treatment with TGF $\beta$.

Nuclear T $\beta$ RI ICD is linked to TGF $\beta$-induced cancer invasion. To explore the generality of the TGF $\beta$-induced pathway identified in this report, we extended our investigation to the human breast carcinoma cell line MDA-MB-231 and the human lung carcinoma cell line A549. By using confocal imaging, we found that TGF $\beta$ treatment of MDA-MB-231 also promotes accumulation of endogenous ICD of T $\beta R I$ in the nucleus, in a TACE- and PKC $\zeta$ - dependent manner, which was found to be associated with the TGF $\beta$ induced invasiveness of the cells (Fig. 7a,b). We observed a similar association between TGF $\beta$-induced nuclear accumulation of T $\beta R I$ ICD and TGF $\beta$-induced invasiveness in the A549 cell line, which also in these cancer cells were regulated by TACE and PKC $\zeta$ (Fig. $7 c, d)$. From these data we conclude that TGF $\beta$-induced invasion of human breast and lung cancer cells correlates with nuclear accumulation of T $\beta R I$ in a TACE- and $\mathrm{PKC} \zeta$-dependent manner.

Nuclear T及RI ICD is observed in human tumours in vivo. To explore whether nuclear accumulation of the T $\beta$ RI ICD occurs in human tumours, we used immunohistochemistry to investigate the expression and localization of T $\beta R I$ in a panel of prostate cancers, renal cell carcinomas and bladder tumours. Nuclear accumulation of T $\beta$ RI ICD was observed in 19 of 19 investigated prostate cancer tissues, in 19 of 24 renal cell carcinomas, and in 21 of 23 bladder tumours, while staining with the H100 antibody to visualize the extracellular part of T $\beta$ RI, showed staining only in the cytoplasm (Fig. 8). No immunohistochemical staining of T $\beta R I$ was observed in control experiment (when the primary antibodies were omitted, Supplementary Fig. S6). Thus, our data demonstrated that nuclear accumulation of T $\beta$ RI ICD is observed in human tumours. 
a

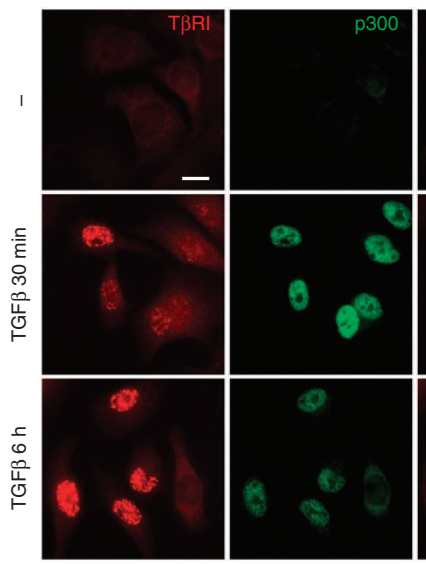

e

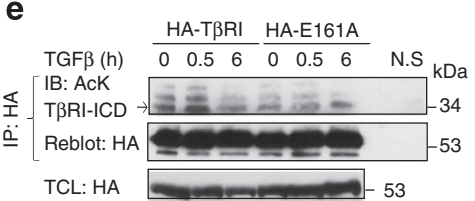

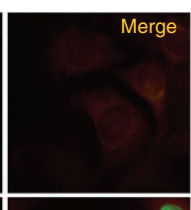
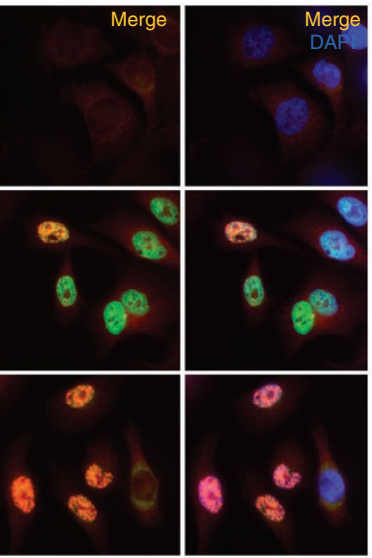

b
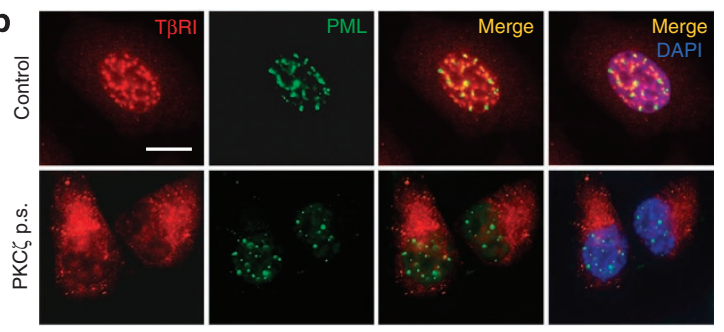

C

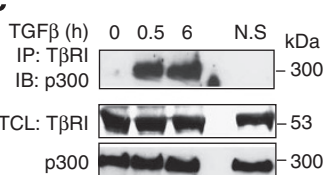

d

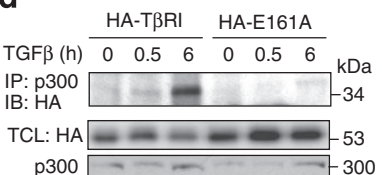

f $\quad \ldots \quad \ldots \quad \mathbf{g}$

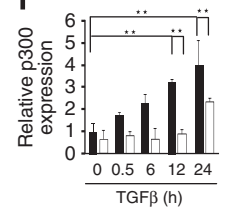

g
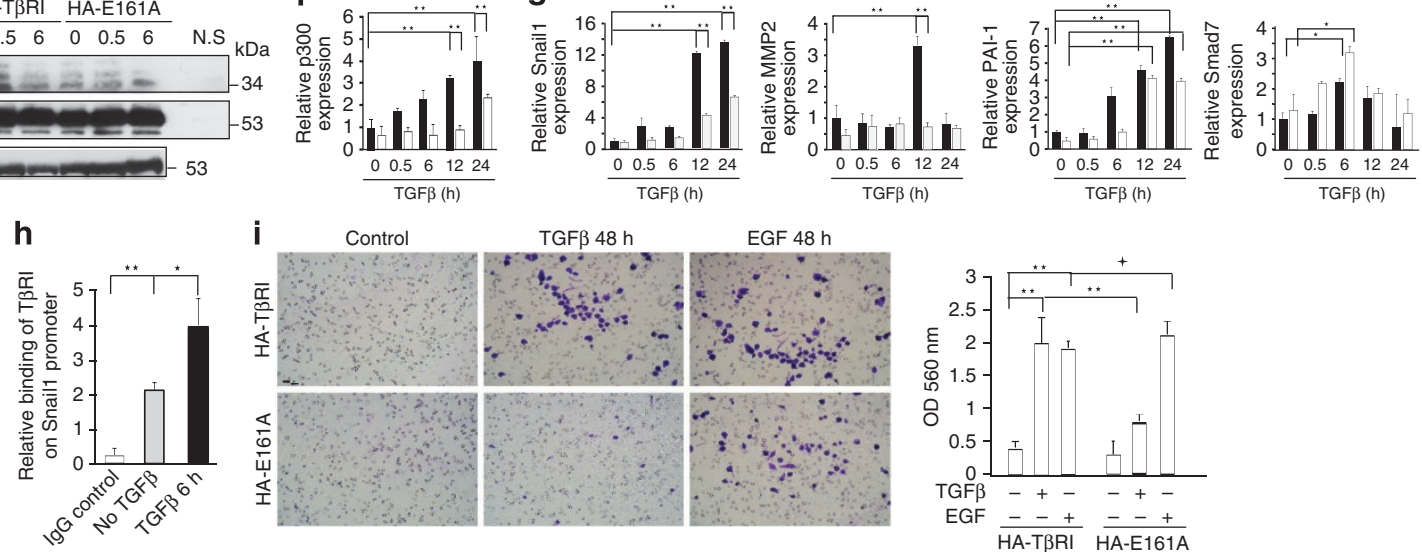

EGF $48 \mathrm{~h}$
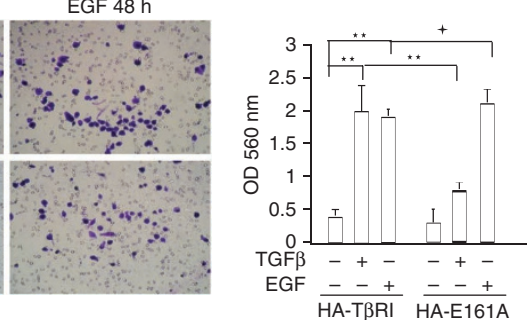

\section{j}

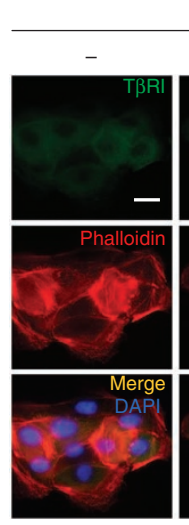

PREC

TGFß $0.5 \mathrm{~h}$
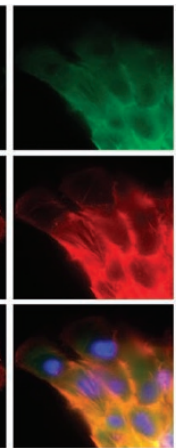

TGF $\beta 6 \mathrm{~h}$
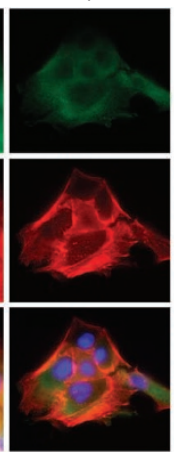

PC-3U

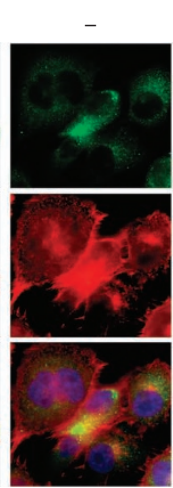

TGF $\beta 0.5 \mathrm{~h}$
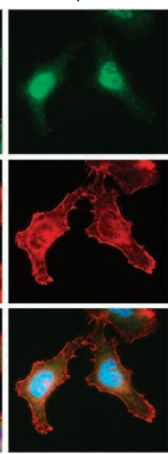

TGF $\beta 6 \mathrm{~h}$
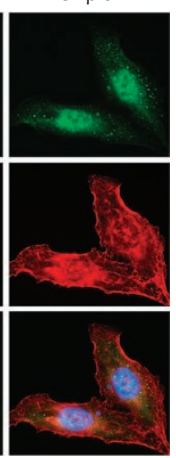

k

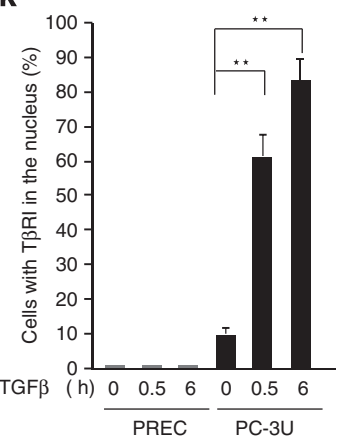

Figure 6 | T $\beta$ RI promotes expression of Snail and invasion of prostate cancer cells in a TGF $\beta$-dependent manner. (a) PC-3U cells were treated with or without TGF $\beta$. Endogenous T $\beta R I$ and p300 are visualized by immunofluorescence using V22 (TRITC) and p300 (FITC) antibodies. Note the TGF $\beta$ induced nuclear accumulation of endogenous T $\beta R \mathrm{R}$ and colocalization with p300 (shown in merge; yellow). (b) PC-3U cells were treated as indicated. Endogenous T $\beta R$ I and PML are shown by immunofluorescence using V22 (TRITC) and PML (FITC) antisera. (c) TGF $\beta$ induces association between endogenous T $\beta R \mathrm{RI}$ and $\mathrm{p} 300$. Cell lysates from PC-3U cells treated with TGF $\beta$ were immunoprecipitated with the V22 antibody against T $\beta R I$ and subjected to immunoblotting with p300 antibody. (d) Cell lysates from PC-3U cells transiently transfected and treated as indicated, were immunoprecipitated with an antibody against $\mathrm{p} 300$ and subjected to immunoblotting with HA antibody. (e) Cell lysates from PC-3U cells, transiently transfected and treated as indicated, were immunoprecipitated with an antibody against HA and subjected to immunoblotting with acetyl-Lys (AcK) antibody. (f, g) qRT-PCR analysis for expression of $p 300$, Snail-1, MMP2, PAl1 and Smad7 was performed on mRNA extracted from PC-3U cells transiently transfected with wt HAT $\beta R$ I (filled bars) or the E161A mutant (open bars) and treated as indicated. (h) Chromatin immunoprecipitation assay for the Snail promoter using V22 antibody against the endogenous T $\beta R I$ in PC-3U cells treated or not with TGF $\beta$. (i) Invasion assay for PC-3U cells, transiently transfected and treated as indicated. Cells were visualized by staining with crystal violet cell stain solution. Right panel presents mean values for optical density (OD) of invasive cells. (j) Immunofluorescence stainings of cytoskeletal reorganization of actin and subcellular localization of T $\beta R$ I in TGF $\beta$-treated primary prostate epithelial cells (PREC) and PC-3U cells for comparison. (k) Quantification of the number of cells in (j) showing endogenous T $\beta R$ I in the nucleus, where $N=200$ cells were counted in each group. ( $\mathbf{a}, \mathbf{b}, \mathbf{j})$ Staining with DAPI was used to visualize cell nuclei. Scale bar $20 \mu \mathrm{m}$. Data in $(\mathbf{f}, \mathbf{g}, \mathbf{h}, \mathbf{i}, \mathbf{k})$ are representative of three independent experiments (mean and s.d). ${ }^{\star} P<0.05$ and ${ }^{\star \star} P<0.005$ (ANOVA except for relative Smad7 expression, where Students $t$-test were used). 
a

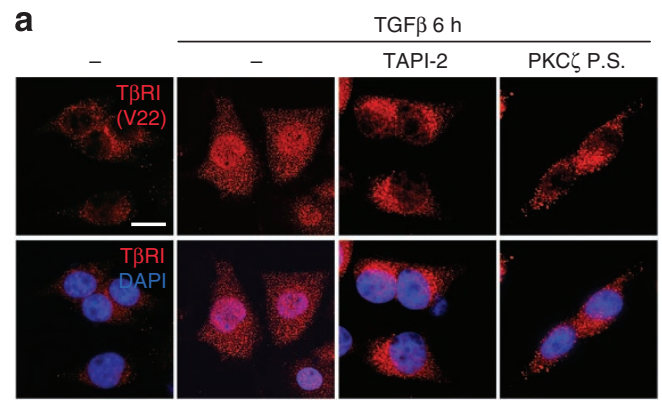

c

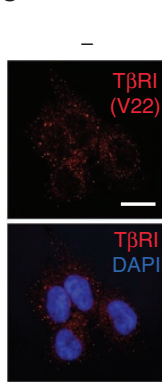

TGF $\beta 6 \mathrm{~h}$

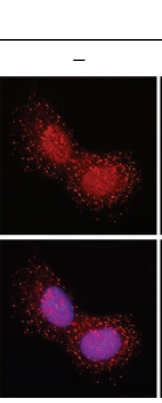

TGF $\beta 6 \mathrm{~h}$

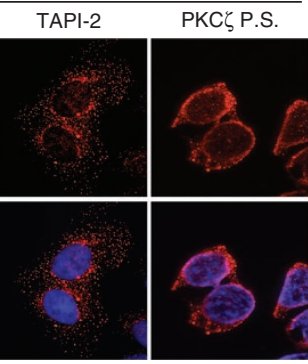

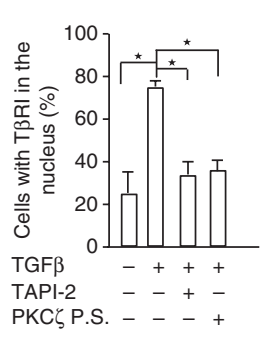

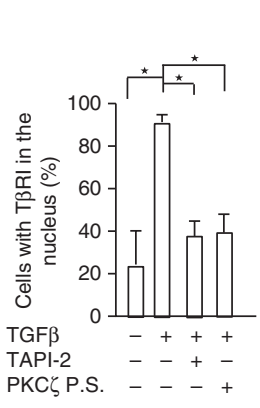

b

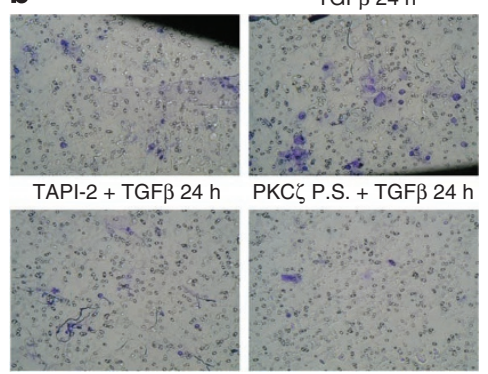

d

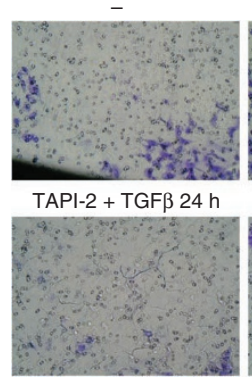

TGF $\beta 24 \mathrm{~h}$

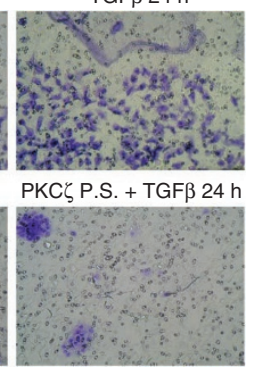

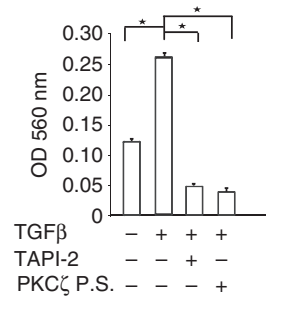

PKC P.S. - - - +

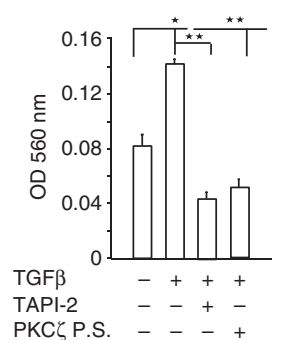

Figure 7 | T $\beta R I$ nuclear localization in human breast and lung carcinoma cells is associated with tumour invasion. (a) Human breast carcinoma (MDA-MB-231) cells were starved and treated with TGF $\beta$ in the presence or absence of the PKC $\zeta$ pseudosubstrate (P.S.) or TAPI-2, as indicated. Endogenous C-terminal T $\beta R I$ was visualized by immunofluorescence using the V22 antibody (TRITC). Quantification of the number of cells showing endogenous T $\beta R \mathrm{R}$ in the nucleus is shown on the right side of the panel (mean \pm s.d., $n=3$ independent experiment, where $N=200-300$ cells where counted in each group, $\left.{ }^{\star} P<0.001, A N O V A\right)$. Scale bar $20 \mu \mathrm{m}$. (b) Invasion assay for MDA-MB-231 treated with TGF $\beta$ in the absence or presence of TAPI-2 and PKC C.S. Cells were visualized by staining with crystal violet cell stain solution. Right panel presents mean values for optical density (OD) of invasive cells. Error bars represents s.d. ( $n=3$ independent experiments, ${ }^{\star} P<0.05$; Students $t$-test). (c) Human lung carcinoma (A549) cell were starved and treated with TGF $\beta$ in the presence or absence of the PKC $\zeta$ P.S or TAPI-2, as indicated. Endogenous C-terminal T $\beta$ RI was visualized by immunofluorescence using the V22 antibody (TRITC). Quantification of the number of cells showing endogenous T $\beta R$ I in the nucleus is shown on the right side of the panel (mean \pm s.d., $n=3$ independent experiment, where $N=200-300$ cells where counted in each group, ${ }^{\star} P<0.0003$, ANOVA). Scale bar $20 \mu \mathrm{m}$. (d) Invasion assay for A549 cells treated with TGF $\beta$ in the absence or presence of TAPI-2 and PKC $\zeta$ P.S. Cells were visualized by staining with crystal violet cell stain solution. Right panel presents mean values for OD of invasive cells. Error bars represents mean \pm s.d. $\left(n=3\right.$ independent experiments; $\left.{ }^{\star} P<0.05,{ }^{\star \star} P<0.002, A N O V A\right)$.

\section{Discussion}

We have provided evidence that T $\beta$ RI undergoes cleavage by TACE in cancer cells and that the ICD of T $\beta R I$ is translocated to the nucleus where it associates with the transcriptional regulator p300 in nuclear PML bodies. Accumulation of the ICD of T $\beta R I$ in the nucleus occurs after TGF $\beta$ stimulation and is dependent on TRAF6,

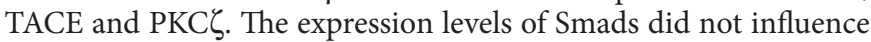
the $\mathrm{PKC} \zeta$-dependent generation of the ICD of T $\beta R I$ as knock down of Smad4 by siRNA, had no effect on the PKC $\zeta$-induced generation of T $\beta$ RI ICD (Supplementary Fig. S7a). Neither did overexpression of Smad2, 3 or 4 in PC-3U cells affect PKC $\zeta$-induced generation of T $\beta$ RI ICD (Supplementary Fig. S7b). Since the TRAF6-binding deficient T $\beta$ RI mutant (HA-E161A) still activates Smad2, while generation of the T $\beta$ RI ICD is impaired, it appears that the canonical Smad pathway can operate independently of the generation of the T $\beta R I$ ICD, which instead correlates with activation of the TRAF6TAK1 - p38 MAPK pathway (Fig. 2a).

Integrins are essential adhesion receptors which are involved in cell migration and extracelullar matrix assembly ${ }^{19}$. TGF $\beta$-induced activation of the p38 MAPK pathway has been demonstrated to be related to integrin signaling and implicated in epithelial-mesenchymal transition in certain cell lines ${ }^{20}$. To investigate a possible relationship between integrin signaling and TGF $\beta$-induced generation of T $\beta$ RI ICD, we used antibodies which promotes or inhibits integrin activation ${ }^{21}$ (TS2 and CD29 antibodies, respectively). No major effects on TGF $\beta$-induced formation of the T $\beta$ RI ICD was observed, when integrins were activated or inhibited (Supplementary Fig. S8).
Exactly how T $\beta$ RI ICD is translocated to the nucleus is the topic of our ongoing investigations. Interestingly, our finding that the ICD of T $\beta$ RI associates with p300 and the Snail promoter, to support transcriptional regulation of a subset of genes, including Snail, MMP2 and p300, correlates with increased invasiveness of cells. Whether the Smad proteins also participitate in the transcriptional complexes is an interesting possibility that remains to be elucidated. Nuclear accumulation of T $\beta$ RI was observed in prostate, breast and lung cancer cells and also in several cancer tissues, but not in primary prostate epithelial cells. Thus the pathway elucidated in this report occurs in different kinds of human tumours and could contribute to tumour progression. Taken together, our data support the notion that the cleavage and nuclear accumulation of T $\beta$ RI is part of a tumour promoting TGF $\beta$ signaling pathway.

\section{Methods}

Cell culture. The human prostate cancer cell lines PC-3U, originating from PC- $3^{22}$ which are known to produce TGF $\beta$ in an autocrine fashion ${ }^{23}$ and LNCaP, were purchased from ATCC and grown in RPMI-1640 with 10\% fetal bovine serum (FBS) and L-glutamine. Wt MEF and TRAF6 ${ }^{-/-}$MEF were grown in Dulbecco's modified Eagle's medium (DMEM) containing 10\% FBS. Normal human primary prostate epithelial cells (PrEC) were purchased from Cambrex Bio Science Walkersville. The cells were grown according to the manufacturer's recommendation in Prostate Epithelial Cell Basal Medium supplemented with Clonetics PrEGM bullet kit. The cells were starved $12-18 \mathrm{~h}$ in medium supplemented with $1 \%$ FBS before TGF $\beta$ stimulation (TGF $\beta 110 \mathrm{ng} / \mathrm{ml}$ (R\&D System, UK).

Antibodies and reagents. Antibodies or antisera against the following proteins were used in immunoblotting or immunofluorescence (IF): HA (Y-11, 1:500 and 1:50 for IF), ubiquitin (P4D1, 1:400), T $\beta$ RI (V22, 1:250 and 1:50 for IF); the 


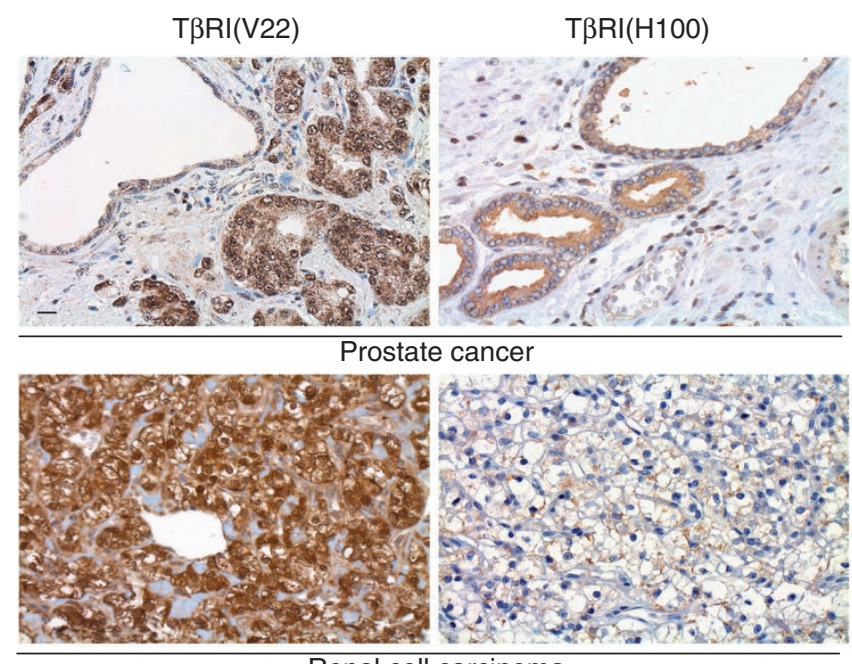

Renal cell carcinoma

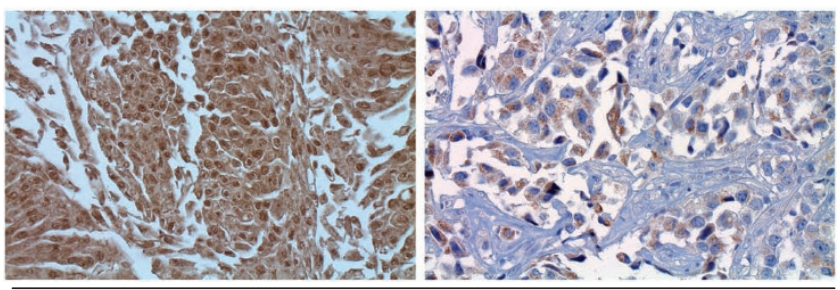

Bladder tumor

Figure 8 | TRRI ICD is localized in nucleus in different kinds of malignant

tumours. Tumour tissues from prostate cancer, renal cell carcinoma and bladder tumour were stained with $\mathrm{V} 22$ and $\mathrm{H} 100$ antibodies, which recognize the intracellular and extracellular domain of T $\beta R I$, respectively. Scale bar $20 \mu \mathrm{m}$.

specificity of this antibody has previously been reported $\left.{ }^{24,25}\right)$ and $\mathrm{H} 100(1: 250)$, TRAF6 (D10, 1:500) and p300 (NM11, 1:200) antibodies were from Santa Cruz Biotechonology; p-Smad2 (1:500) and T $\beta R I$ (VPN, 1:500) antisera were generated in rabbits in-house; lamin A (1:1,000), TACE/ADAM17 (1:50 for IF), pPKC $\zeta / \lambda$ (Thr410/403, 1:1,000), PKC $(1: 1,000)$, p-p38 (1:1,000), p38 (1:1,000), Smad2 $(1: 1,000)$ and acetyl-Lys antibodies $(1: 1,000)$ were from Cell Signaling. Antibody against TRAF6 C-term was from ZYMED Laboratories (1:500); UbK63 antibody $(1: 1,000)$ was from Enzo Life Sciences. UbK48 Clone Apu 207 antibody $(1: 1,000)$ was a kind gift from V.M. Dixit, Genetech; antibodies against $\beta$-actin $(1: 10,000)$, $\beta$-tubulin (1:1,000), HA (1:1,000) were from Sigma.

The mouse monoclonal TS2/16 antibody (a kind gift from Dr K. Rubin) was used at a concentration of $20 \mu \mathrm{g} / \mathrm{ml}$ to activate $\beta 1$-integrin and a rat anti-human CD29 antiserum, purchased from BD Pharmingen, was used at a concentration of $10 \mu \mathrm{g} / \mathrm{ml}$ to inactivate $\beta 1$-integrin respectively. Horseradish peroxidase-coupled secondary antibodies were from Sigma. In some experiments, either goat anti-mouse IgG, light chain specific or mouse anti-rabbit IgG, light chain specific antisera from Jackson ImmunoResearch Laboratories, were used. 4,6-Diamidino2-phenylindole dihydrochloride (DAPI) fluorescent dye to visualize cell nuclei by microscopy was purchased from Merck and TRITC labelled phalloidin from Sigma. Alexafluor 555 was purchased from Invitrogen.

Protein-G Sepharose was from GE Healthcare; LumiLight Western blotting substrate and Pefabloc were from Roche, PageRuler prestained protein ladder was from Fermentas; TAPI-2 was from BIOMOL Research Laboratories Inc., and used at concentrations of $10-20 \mu \mathrm{M}$. PKC $\zeta$ pseudosubstrate was from TOCRIS Bioscience. The PKC activator phorbol 12-myristate 13-acetate (PMA, referred to as TPA in our paper) and a TBRI inhibitor (SB505124), were purchased from Sigma and used at concentrations of $100 \mathrm{nM}$ and $10 \mu \mathrm{M}$, respectively. All inhibitors were added $1 \mathrm{~h}$ before TGF $\beta$ stimulation.

Protein analyses. The cells were starved for $12-18 \mathrm{~h}$ and then stimulated with TGF $\beta$ for indicated time periods, washed twice in ice-cold PBS and lysed in icecold lysis buffer $(150 \mathrm{mM} \mathrm{NaCl}, 50 \mathrm{mM}$ Tris $\mathrm{pH} 8.0,0.5 \%(\mathrm{v} / \mathrm{v})$ DOC, $1 \%(\mathrm{v} / \mathrm{v})$ NP40, 10\% (v/v) glycerol, $1 \mathrm{mM}$ aprotinin, $1 \mathrm{mM}$ Pefabloc and $2 \mathrm{mM}$ sodium orthovanadate). After centrifugation, supernatants were collected and protein concentrations were determined by BCA protein measurement kit (Nordic Biolabs). Equal amount of protein from total cell lysate and immunoprecipitation were run in SDS-PAGE using 6, 10, 12 or $4-12 \%$ gradient polyacrylamide gels, blotted on to polyvinylidine difluoride membranes and subjected to immuno- blotting, as previously described ${ }^{25}$. In vitro and in vivo ubiquitination assays, immunofluorescence and transient transfections were performed, as previously described $^{5,26,27}$. HA, TACE, H100 and V22 antibodies were diluted 1:50 when used for immunofluorescence. Photo micrographs were obtained by Zeiss 510 Meta (Carl Zeiss Microimaging, Inc.) with a digital camera (RET-EXi-F-M-12-C) from Q-imaging.

Nuclear fractionation assays. Two different protocols for nuclear fractionation were used to examine T $\beta R I$ accumulation in the nucleus in response to TGF $\beta$.

The first used for cell fractionation, has earlier been described ${ }^{27}$ and was used in the experiments shown in Figures $1 \mathrm{~b}$ and $5 \mathrm{~d}$.

The second was applied in experiments shown in Figure $3 \mathrm{~b}$ and used Nuclear Complex Co-IP kit purchased from Active Motif. Cells in a 10-cm dish were washed twice with ice-cold PBS, and then scraped and collected into $1 \mathrm{ml}$ ice-cold PBS; after centrifugation at 1,500 r.p.m. for $5 \mathrm{~min}$ at $4^{\circ} \mathrm{C}$, the cell pellet was gently resuspended in $500 \mu \mathrm{l}$ Hypotonic Buffer and incubated on ice for $15 \mathrm{~min}$. Twenty five $\mu \mathrm{l}$ of Detergent Solution was added and gently mixed and centrifuged at $14,000 \times g$ for $30 \mathrm{~s}$, at $4^{\circ} \mathrm{C}$. The nuclear pellet was resuspended in $100 \mu \mathrm{l} \mathrm{Complete}$ Digestion Buffer, vortexed gently for $2 \mathrm{~s}$ after adding $0.5 \mu \mathrm{l}$ of Enzymatic Shearing Cocktail, thereafter incubated for $10 \mathrm{~min}$ at $37^{\circ} \mathrm{C}$. The nuclear lysates were vortexed gently after $2 \mu \mathrm{l}$ of $0.5 \mathrm{M}$ EDTA had been added to stop the reaction, and then incubated on ice for $5 \mathrm{~min}$, centrifuged $\left(14,000 \mathrm{~g}, 10 \mathrm{~min}, 4^{\circ} \mathrm{C}\right)$, and the supernatant was collected for immunoprecipitation.

Invasion assay. Invasion assays were performed by using the CytoSelect ${ }^{\text {tid }}$ Cell Invasion Assay (Cell Biolabs, Inc., San Diego, CA). The basement membrane layer of the cell culture inserts were rehydrated in $300 \mu \mathrm{l}$ serum-free RPMI-1640, and $2 \times 10^{6}$ cells were seeded into the upper area of the chambers in serum-free RPMI 1640 with or without TGF $\beta$. Lower wells of the invasion plates were filled with $500 \mu \mathrm{l}$ RPMI, supplemented with 10\% FBS. Non-invasive cells were removed from the upper chamber and invasive cells were photographed by a Leica DMR light microscope, after staining with crystal violet cell stain solution. Colorimetric quantification was performed by transfer inserts into $200 \mu \mathrm{l}$ of extraction solution for $10 \mathrm{~min}$. Optical density (O.D.) at $560 \mathrm{~nm}$ was determined for extracts transferred to a 96-well microtiter plate using a plate reader.

Plasmids and DNA transfections. GFP-caT $\beta$ RI was constructed by cloning full length caT $\beta R I$ between the immediate early promoter of CMV and the EGFP coding sequence; the C-terminus of caT $\beta R I$ was fused to the N-terminus of pEGFP-N3 vector. The pcDNA3 and wt PKC $\zeta$ plasmids were from Addgene. HA-caT $\beta R I$ and HA-T $\beta R I$ KR (kinase dead (KD) mutant) with HA fused to the C-terminus of TRRI, were kind gifts from P. ten Dijke (University of Leiden, The Netherlands). Expression vectors for C-terminally tagged HA-tagged G120I mutant for caT $\beta R I$ were generated by PCR and the mutation was confirmed by sequencing. The caTBRI-E161A plasmid with HA fused to the C-terminus of TRRI was described before ${ }^{5}$. HA-T $\beta$ RI with HA inserted between amino acid residues 27 and 28, was a kind gift from Dr S. Corvera (University of Massachusetts Medical School, Worcester, USA). 3xHA-tagged wild-type ubiquitin, K48- and K63-only ubiquitin mutants were kind gifts from V.M Dixit (Genentech, San Francisco, CA). Expression vector for GST-T $\beta R I$ fusion protein, encoding the complete cytoplasmic part (amino acid 148-503) of ca T $\beta R I$ (T204D) has been described previously ${ }^{28}$.

siRNA transfection. Twenty-one-base pair siRNA duplexes for T $\beta R I$ (also known as ALK5), SMART pool siRNA for TRAF6 as previously described ${ }^{5}$, and a non-specific control siRNA, were synthesized by Dharmacon Research (Lafayette, CO). The sequence for T $\beta R I$ siRNA duplex was $5^{\prime}$ AAC AUA UUG CUG CAA CCA GGA $3^{\prime}$, and the non-specific duplex oligo 5' AAC AGU CGC GUU UGC GAC UGG ${ }^{\prime}$. PKC $\zeta$ siRNA (h2) was from Santa Cruz biotechnology. The siRNA was transfected with Oligofectamine (Invitrogen) according to the manufacturer's protocol.

Expression analysis. Total RNA was isolated from cells using RNeasy Minikit (Qiagen) and Thermoscript RT-PCR System (Invitrogen) was used for the preparation of double-stranded cDNA. qRT-PCR was performed using Power SYBR Green PCR Mastermix (Applied Biosystems) with the Stratagene MX3000P. The following primers were used for qRT-PCR.

TßRI, forward primer (FP), TGTTGGTACCCAAGGAAAGC, reverse primer (RP), CACTCTGTGGTTTGGAGCAA; p300, FP, GGGACTAACCAATGGTGGTG, RP, GTCATTGGGCTTTTGACCAT; SNAIL 1, FP, GAGCATACAGCCCCATCACT, RP, GGGTCTGAAAGCTTGGACTG; Smad7, FP, TCCTGCTGTGCAAAGTGTTC, RP, TCTGGACAGTCTGCAGTTGG; MMP 2 , FP, AGGCCGACATCATGGTACTC, RP, GGTCAGTGCTGGAGAAGGTC; PAI 1, FP,CTCTCTCTGCCCTCACCAAC, RP, GTGGAGAGGCTCTTGGTCTG.

Chromatin immunoprecipitation. ChIPs were performed for three or more biological replicates. The ChIP protocol provided by Abcam, Cambridge UK was followed. The chromatin was precipitated using the V22 rabbit antibody (Santa Cruz). After purification, the DNA was amplified using qRT-PCR to analyze ChIP DNA in triplicate. The following primers were used for ChIP; Snaill forward primer, GGACTCAGGGAGACTCATGG, reverse primer, GGGTCTACGGAAA CCTCTGG. 
Histology of human tumours. Tissue microarrays (TMAs) of malignant tissues, containing multiple samples from different patients with prostate cancer, renal cell carcinoma and bladder cancer produced by the Human Proteome Atlas (HPA) facility (http://www.proteinatlas.org) were stained using anti-T $\beta R I$ antibodies (V22 and H100). Pictures of stained TMA sections were taken with an ALTRA 20 soft imaging system and an Olympus BX45 microscope. Ethical permit to use decoded, tumour tissues for generation of tissue slides or TMA was granted by the Uppsala ethical review board in full agreement with the Swedish Ethical Review Act.

Statistical analysis. $P$ values were calculated by Student's two-tailed $t$-test or One-way ANOVA, as indicated in Figure legends. Analyses were performed in a Statistica software program. Values are expressed as mean \pm s.d., of three or more independent experiments performed in triplicates, unless otherwise indicated. $P$ values of $<0.05$ were considered statistically significant.

\section{References}

1. Groppe, J. et al. Cooperative assembly of TGF-beta superfamily signaling complexes is mediated by two disparate mechanisms and distinct modes of receptor binding. Mol. Cell 29, 157-168 (2008).

2. Massagué, J. TGFbeta in Cancer. Cell 134, 215-230 (2008).

3. Heldin, C.- H., Landstrom, M. \& Moustakas, A. Mechanism of TGF- $\beta$ signaling to growth arrest, apoptosis and epithelial-mesenchymal transition. Curr. Opion in Cell Biology 21, 1-11 (2009).

4. Hayes, S., Chawla, A. \& Corvera, S. TGF beta receptor internalization into EEA1-enriched early endosomes: role in signaling to Smad2. J. Cell Biol. 158, 1239-1249 (2002)

5. Sorrentino, A. et al. The type I TGF-beta receptor engages TRAF6 to activate TAK1 in a receptor kinase-independent manner. Nat. Cell Biol. 10, 1199-1207 (2008).

6. Yamashita, M., Fatyol, K., Jin, C., Wang, X., Liu, Z. \& Zhang, Y. E. TRAF6 mediates Smad- independent activation of JNK and p38 by TGF-beta. Mol. Cell 31, 918-924 (2008).

7. Liu, C., Xu, P., Lamouille, S., Xu, J. \& Derynck, R. TACE-mediated ectodomain shedding of the type I TGF-beta receptor downregulates TGF-beta signaling. Mol. Cell 35, 26-36 (2009).

8. Hershko, A. \& Ciechanover, A. The ubiquitin system. Annu. Rev. Biochem. 67, 425-479 (1998).

9. Ikeda, F., Crosetto, N. \& Dikic, I. What determines the specificity and outcomes of ubiquitin signaling? Cell 143, 677-681 (2010).

10. Huovila, A. P., Turner, A. J., Pelto-Huikko, M., Kärkkäinen, I. \& Ortiz, R. M. Shedding light on ADAM metalloproteinases. Trends Biochem. Sci. 30, 413-422 (2005).

11. Wang, S. E. et al. Transforming growth factor beta engages TACE and ErbB3 to activate phosphatidylinositol-3 kinase/Akt in ErbB2-overexpressing breast cancer and desensitizes cells to trastuzumab. Mol Cell. Biol. 18, 5605-5620 (2008).

12. Jin, G. et al. A continuous fluorimetric assay for tumour necrosis factor-alpha converting enzyme. Anal. Biochem. 302, 269-275 (2002).

13. Chow, J. P., Fujikawa, A., Shimizu, H., Suzuki, R. \& Noda, M. Metalloproteinase- and gamma-secretase-mediated cleavage of proteintyrosine phosphatase receptor type Z. J. Biol. Chem. 283, 30879-30889 (2008).

14. Feng, Y. \& Longmore, G. D. The LIM protein Ajuba influences Interleukin-1Induced NF-kB activation by affecting the assembly and activity of the protein kinase Cz/p62/TRAF6 signaling complex. Mol. and Cell. Biol. 25, 4010-4022 (2005).

15. Moscat, J., Diaz-Meco, M. T. \& Wooten, M. W. Of the atypical PKCs, Par-4 and p62: recent understandings of the biology and pathology of a PB1-dominated complex. Cell Death Differ. 11, 1426-1437 (2009).

16. Wheeler, D. L., Ness, K. J., Oberley, T. D. \& Verma, A. K. Protein kinase Cepsilon is linked to 12-O-tetradecanoylphorbol-13-acetate-induced tumour necrosis factor-alpha ectodomain shedding and the development of metastatic squamous cell carcinoma in protein kinase Cepsilon transgenic mice. Cancer Res. 63, 6547-6555 (2003).

17. Bernardi, R., Papa, A. \& Pandolfi, P. P. Regulation of apoptosis by PML and the PML- NBs. Oncogene 27, 6299-6312 (2008).

18. Thiery, J. P., Acloque, H., Huang, R. Y. \& Nieto, M. A. Epithelial-mesenchymal transitions in development and disease. Cell 139, 871-890 (2009).

19. Anthis, N. J. \& Campbell, I. D. The tail of integrin activation. Trends Biochem. Sci. 36, 191-198 (2011).

20. Bhowmick, N. A., Zent, R., Ghiassi, M., McDonnell, M. \& Moses, H. L. Integrin beta 1 signaling is necessary for transforming growth factor-beta activation of p38 MAPK and epithelial plasticity. J. Biol. Chem. 276, 46707-46713 (2001).
21. Byron, A., Humphries, J. D., Askari, J. A., Craig, S. E., Mould, A. P. \& Humphries, M. J. Anti-integrin monoclonal antibodies. J. Cell Sci. 122, 4009-4011 (2009).

22. Franzen, P., Ichijo, H. \& Miyazono, K. Different signals mediate transforming growth factor-beta 1-induced growth inhibition and extracellular matrix production in prostatic carcinoma cells. Exp. Cell Res. 207, 1-7 (1993).

23. Ikeda, T. et al. Human transforming growth factor type $\beta 2$ : production by a prostatic adenocarcinoma cell line, purification, and initial characterization. Biochemistry 26, 2406-2410 (1987).

24. Castanares, C. et al. Signaling by ALK5 mediates TGF-beta-induced ET-1 expression in endothelial cells: a role for migration and proliferation. J. Cell Sci. 120, 1256-1266 (2007).

25. Medici, D. et al. Conversion of vascular endothelial cells into multipotent stemlike cells. Nat. Med. 16, 1400-1406 (2010).

26. Edlund, S. et al. Transforming growth factor $-\beta 1$ (TGF- $\beta$ )-induced apoptosis of prostate cancer cells involves Smad7-dependent activation of p38 by TGF- $\beta$ activated kinase 1 and mitogen-activated protein kinase kinase 3. Mol. Biol. Cell 2, 529-544 (2003).

27. Edlund, S. et al. Interaction between Smad7 and $\beta$-catenin: importance for transforming growth factor beta-induced apoptosis. Mol. Cell Biol. 4, 1475-1488 (2005).

28. Yakymovych, I., Engström, U., Grimsby, S., Heldin, C.- H. \& Souchelnytskyi, $\mathrm{S}$. Inhibition of transforming growth factor-beta signaling by low molecular weight compounds interfering with ATP- or substrate-binding sites of the TGF beta type I receptor kinase. Biochemistry 41, 11000-11007 (2002).

\section{Acknowledgments}

We are grateful to S. Corvera, I. Dikic, V.M. Dixit, J. Inoue, A. Jurek, C. Kampf, K. Miyazono, A. Moustakas, F. Pontén, K. Rubin, U. Singh, S. Souchelnytskyi, P. ten Dijke and B. Westermark for providing reagents. We have used the Cell Analysis and Uppsala Genome Center core facilities at the Rudbeck Laboratory, Uppsala University. We appreciate the contribution to our study from Susanne Grimsby, Alessandro Sorrentino and Ihor Yakymovych. We thank Lena Claesson-Welsh and our colleges at the Ludwig Institute for Cancer Research, Uppsala Branch for valuable discussions. This work was supported by the Ludwig Institute for Cancer Research and grants to ML from the Swedish Medical Research Council, the Swedish Cancer Society, the Torsten and Ragnar Söderbergs Foundation, Umeå University, Lions Cancerfond in Umeå and ALF. J.E. is the recipient of a Science Foundation Ireland Stokes Professorship Award (07/SK/B1242b). J.E. and M.T. B.-A. are supported by Science Foundation Ireland (SFI/10/IN.1/B2986).

\section{Author contributions}

Y.M., R.S., N.T. and M.E. contributed equally to this work. Y.M. and S.K.G. performed nuclear fractionation assays. R.S. performed invasion assays, ChIP-assays and created and characterized the HA-TßRI-G120I mutant. Y.M., R.S., M.E., S.K.G. and A.H. performed immunofluorescence assays. N.T. and R.S. constructed the GFP-T $\beta R I$ and performed experiments together with S.K.G to investigate its localization. R.S and N.T performed ubiquitination assays. R.S., S.K.G. and N.T. performed qRT-PCR experiments. Y.M., R.S., N.T., S.K.G., M.Y., A.H., H.D., M.T.B.-A. and J.E. performed immunoblot experiments. M.L. investigated immunohistochemical stainings of tumours. All authors analysed and discussed the data. M.E. and Y.M. contributed to the preparation of the Material and Method section. Y.M performed all statistical analysis together with R.S. Y.M. prepared the final figures for publication. M.L. coordinated the project. C.-H.H. and M.L. supervised the project and wrote the manuscript.

\section{Additional information}

Supplementary Information accompanies this paper at http://www.nature.com/ naturecommunication

Competing financial interests: The authors declare no competing financial interests.

Reprints and permission information is available online at http://npg.nature.com/ reprintsandpermissions/

How to cite this article: Mu, Y. et al. TRAF6 ubiquitinates TGF $\beta$ type I receptor to promote its cleavage and nuclear translocation in cancer. Nat. Commun. 2:330 doi: $10.1038 /$ ncomms1332 (2011).

License: This work is licensed under a Creative Commons Attribution-NonCommercialNoDerivative Works 3.0 Unported License. To view a copy of this license, visit http:// creativecommons.org/licenses/by-nc-nd/3.0/ 